\title{
Los despoblados en el paisaje de las Tierras Altas de Yanguas y de San Pedro (Soria): pueblos desocupados, pueblos abandonados y pueblos en ruinas
}

\section{RESUMEN}

La presencia de un número muy alto de despoblados constituye una de las características más significativas del paisaje de la comarca soriana de las Tierras Altas, especialmente en el territorio que perteneció a las comunidades de villa y tierra medievales de Yanguas y de San Pedro Manrique. Se realiza un inventario completo de estos pueblos deshabitados y se analizan su origen y su evolución histórica, así como los factores y las circunstancias de su vaciamiento demográfico. Se los ha clasificado finalmente teniendo en cuenta su nivel de conservación y el número de personas que aún residen en ellos.

\section{RÉsumÉ}

Les villages inhabités dans le paysage des Hautes Terres de Yanguas et de San Pedro (Soria): villages inoccupés, villages abandonnés et villages en ruine.- La présence d'un très haut nombre de villages inhabités constitue l'un des caractères les plus significatifs du paysage de la contrée des Hautes Terres de Soria, spécialement dans le territoire que a appartenu aux communautés médiévales de villa y tierra de Yanguas et de San Pedro Manrique. On réalise dans ce territoire un inventaire complet de ces villages inhabités; son origine et son évolution historique sont analysés, ainsi que les facteurs et les circonstances de son

\section{CARACTERES GENERALES \\ DE LAS TIERRAS ALTAS DE SORIA Y DELIMITACIÓN DEL ÁREA DE ESTUDIO}

$E^{1}$ extremo nororiental de la provincia de Soria, limítrofe con La Rioja, está ocupado por montañas de mediana altitud y perfil alomado, frías y subhúmedas, que se encuentran mayoritariamente deforestadas y con- vidange démographique. Ils ont été classés finalement en fonction de leur niveau de conservation et du nombre de personnes vivant encore en eux.

\section{Abstract}

Uninhabited villages in the landscape of the Yanguas and San Pedro Highlands (Soria): unoccupied villages, abandoned villages and ruined villages.- The presence of a very high number of uninhabited villages is one of the most significant characteristics of the landscape of the Soria district of the Highlands, especially in the territory which belonged to the Yanguas and San Pedro Manrique medieval communities of villa y tierra. Is it a complete inventory of these uninhabited villages and discusses its origin and its historical evolution. It has also sought the factors and circumstances of its demographic emptying. It has been classified them finally given their level of conservation and the number of people who still reside in them.

\section{Palabras clave/Mots clé/Keywords}

Paisaje rural, áreas de montaña, despoblación, pueblos deshabitados. Paysage rural, zones de montagne, dépeuplement, villages inhabités. Rural landscape, mountain areas, depopulation, uninhabited villages.

servan grandes áreas de pastizal que fueron dedicadas durante siglos a la ganadería ovina trashumante (Bachiller Martínez y Sancho de Francisco, 1990). Conforman estas montañas un ámbito de alrededor de $1.200 \mathrm{~km}^{2}$ de extensión y una altura media próxima a los $1.250 \mathrm{~m}$, bien diferenciado por su configuración geomorfológica, su cubierta vegetal y su ocupación humana, así como por sus significados históricos y culturales y peculiar paisaje. 


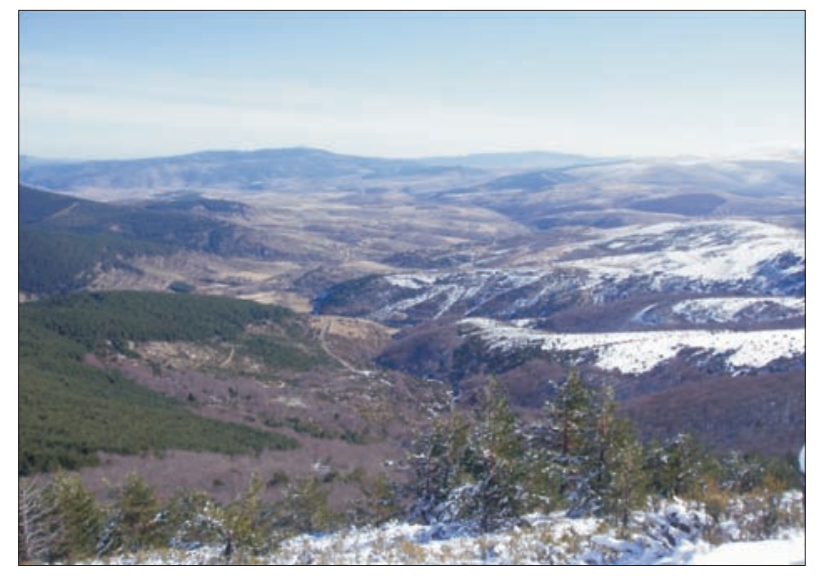

FIg. 1. Panorama de las Tierras Altas de Yanguas y de San Pedro Manrique desde la cumbre de la Avellanosa $(1.758 \mathrm{~m})$ en la sierra de Montes Claros. Al fondo, la sierra de La Alcarama (1.719 m).

Encuadrado en la rama septentrional de la cordillera ibérica, entre los elevados macizos del Urbión-Cebollera, al noroeste, y del Moncayo, al sureste, y repartido entre las cuencas hidrográficas del Duero y el Ebro, este ámbito en su conjunto fue conocido tradicionalmente como «la Sierra»y, según sus sectores, como «la sierra de Alba», «la sierra de Montesclaros», «la sierra de Cameros Viejo»o «la sierra de La Alcarama». Más recientemente (por su evidente altitud y su básica correspondencia con el área histórica de las tierras vinculadas durante el Antiguo Régimen a varias villas - San Pedro Manrique, Yanguas, Magaña y Ágreda - y a varios sexmos de la jurisdicción de la propia ciudad de Soria) ha sido denominado «Tierras Altas» (Muñoz Jiménez, 2008).

Al igual que el de la Tierra de Cameros, que la prolonga en el sector meridional de la comunidad autónoma de La Rioja, el relieve de esta comarca soriana está modelado sobre un roquedo mesozoico de facies continental fuertemente deformado por la tectónica terciaria, en el que los cambios de litología (margas, margocalizas, areniscas y calizas) son numerosos y frecuentes. Su organización topográfica está muy lejos de ser la propia de una barrera montañosa, en la que el relieve se articula en torno a una línea de cumbres principal elevada y continua, capaz de interferir eficazmente los flujos atmosféricos y de potenciar las diferencias de exposición. Por el contrario, abundan las alineaciones y los cordales de altitud relativamente homogénea y moderada densidad (con cumbres alomadas e incluso aplanadas), que no son capaces de obstaculizar el viento y pueden ser persistentemente batidas por él (Sanz Pérez y Pascual Arribas, 2001). La altura que en dichas alineaciones y cordales se alcanza,

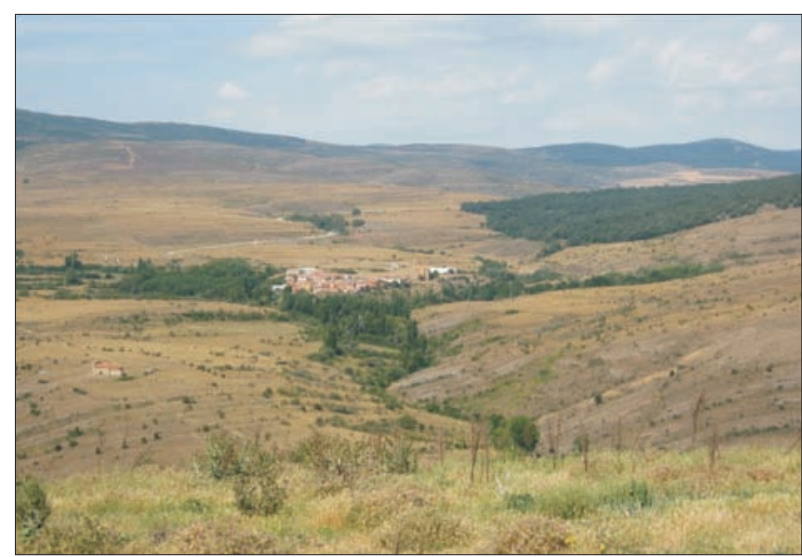

FIG. 2. Cabecera del valle del río Cidacos desde la sierra de Alba $(1.560 \mathrm{~m})$

entre 1.500 y $1.900 \mathrm{~m}$, sí es suficiente, sin embargo, para que las precipitaciones en forma de nieve sean frecuentes, aunque no para que la cubierta nival alcance en sus partes altas espesores especialmente significativos.

En la mayor parte del de las Tierras Altas la temperatura media anual no llega a los $10,0{ }^{\circ} \mathrm{C}$, la temperatura media del mes más frío (enero) varía entre los $2,0^{\circ} \mathrm{C}$ y los $0,5^{\circ} \mathrm{C}$ y la del mes más cálido (julio) entre los $19,0^{\circ} \mathrm{C}$ y los $17,5^{\circ} \mathrm{C}$; la pluviosidad media anual oscila entre los $700 \mathrm{~mm}$ y los $850 \mathrm{~mm}$, al tiempo que el número de días de nevada crece conforme a la altitud de 15 a 25. Otros rasgos del clima son la duración del frío (entre seis y nueve meses con menos de $10,0{ }^{\circ} \mathrm{C}$ de media; más de cien días de helada al año), la dureza térmica del invierno (estación en la que la temperatura máxima de, al menos, el $40 \%$ de los días no llega a los 5,0 ${ }^{\circ} \mathrm{C}$ ) y la reducida extensión del verano meteorológico (sólo en dos meses, julio y agosto, la temperatura media puede acercarse a los 18,0 ㄷ) (Archilla, 1987; García Fernández, 1986; Ortega Villazán, 1992).

A diferencia de lo que ocurre en los vecinos macizos de Cebollera y Urbión, las Tierras Altas no aparecen como un espacio de montaña esencialmente forestal ni caracterizado por el nivel de conservación o la densidad de su vegetación natural. De los hayedos, robledales y encinares potenciales sólo quedan manchas o retazos, acogidos casi siempre en dehesas municipales, de modo que las formaciones seriales (eriales, pastizales, pastizales arbolados, matorrales, montes abiertos, etc.) resultantes de los usos que el territorio ha tenido a lo largo del tiempo y del abandono de la mayor parte de ellos en las últimas décadas son las que dominan y marcan prioritariamente una cobertura vegetal en franca evolución, donde cada vez alcanzan mayor trascendencia visual las plantaciones 


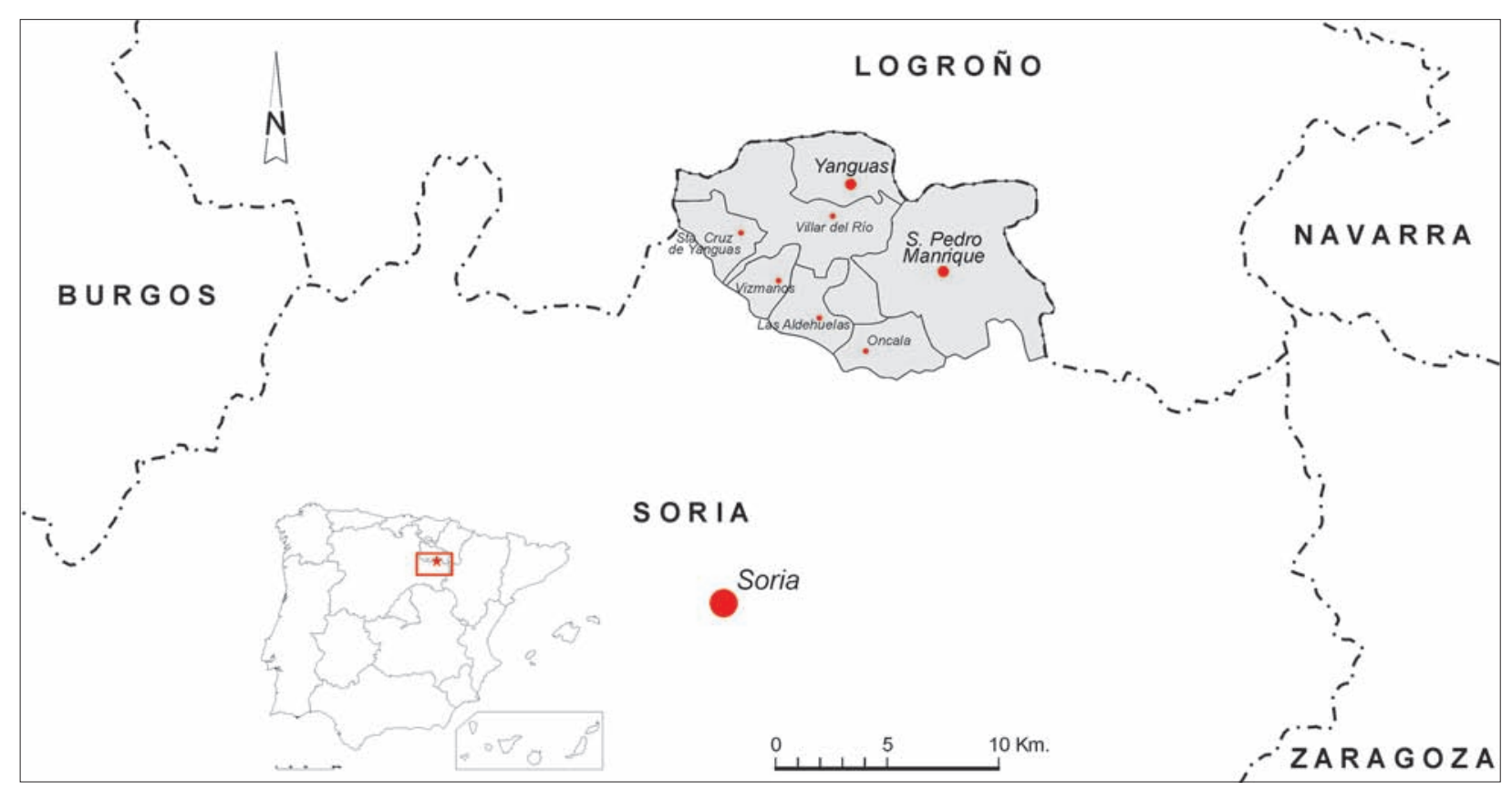

FIg. 3. Localización de las Tierras Altas de Yanguas y de San Pedro Manrique, coincidentes con los altos valles de los ríos Cidacos y Linares, vertientes al Ebro.

de coníferas introducidas en la segunda mitad del siglo xx (Bachiller Martínez, 2008; Muñoz Jiménez, 2008).

Sólo el $32 \%$ de la Tierras Altas sorianas corresponde a la cuenca hidrográfica del Duero y tiene como ejes de drenaje principales a los ríos Tera y Merdancho. El $68 \%$ restante pertenece a la cuenca hidrográfica del Ebro, al cual se vierten sus aguas a través de los ríos Alhama y Cidacos, que tienen su nacimiento y su tramo superior en el área, y de sus afluentes, entre los que destaca el río Linares (también denominado río Mayor), tributario del primero. Los caracteres territoriales y paisajísticos de la comarca se manifiestan con particular intensidad y claridad en los altos valles de esta vertiente nororiental, separados del resto de la provincia de Soria por las montañas, algo más destacadas, que marcan la divisoria de aguas, y difícilmente comunicados con la vecina Rioja por estrechas y vigorosas gargantas. Por ello se ha optado por centrar el análisis en los altos valles, contiguos, del Cidacos y el Linares (aguas arriba de las poblaciones riojanas de Enciso y Cornago), teniendo en cuenta además que coinciden con las viejas comunidades de villa y tierra de Yanguas y de San Pedro y que son el sector donde las consecuencias del vaciamiento demográfico y del abandono de los muy numerosos núcleos de población, registrado por toda la comarca desde mediados del pasado siglo, son especialmente evidentes (Martín Jiménez, 2008).

\section{DESPOBLACIÓN RECIENTE Y SITUACIÓN DEMOGRÁFICA ACTUAL EN LAS TIERRAS ALTAS DE YANGUAS Y DE SAN PEDRO: EMIGRACIÓN MASIVA Y ABANDONO DE LOS NÚCLEOS HABITADOS}

En el año 1950 el territorio de los altos valles de los ríos Cidacos y Linares, situados en la parte norte vertiente al Ebro de las Tierras Altas sorianas, contaba con una población total de 6.833 habitantes $\left(13,89\right.$ habs $\left./ \mathrm{km}^{2}\right)$ y se encontraba dividido en más de cuarenta términos municipales. En la actualidad (después de un drástico proceso de vaciamiento demográfico y de reordenación administrativa desarrollados fundamentalmente en los años sesenta y setenta del siglo $\mathrm{xx}$ ) sólo residen en él 1.169 personas $\left(2,37\right.$ habs. $\left./ \mathrm{km}^{2}\right)$ y el número de municipios se ha reducido a menos de la decena, concretamente a siete. El alto valle del Cidacos, correspondiente a la antigua Tierra de Yanguas, se reparte entre cinco municipios (Yanguas, Santa Cruz de Yanguas, Villar del Río, Vizmanos y Las Aldehuelas), en el conjunto de los cuales el censo de 2014 sólo registra 457 habitantes (1,66 habs./ $\mathrm{km}^{2}$ ); y el alto valle del Linares, correspondiente a la antigua Tierra de San Pedro, se divide entre dos (Oncala y San Pedro Manrique), que, según el citado censo, suman 712 habitantes $\left(3,16\right.$ habs. $\left.\mathrm{km}^{2}\right)$. 
Cuadro I. Superficie, poblamiento y población de los siete municipios de las Tierras Altas de Yanguas y San Pedro

\begin{tabular}{|c|c|c|c|}
\hline TierRa de Yanguas (alto valle del Cidacos) & Superficie (ha) & Habitantes en 2014 & Pueblos \\
\hline Yanguas & 5.330 & 123 & 5 \\
\hline Santa Cruz de Yanguas & 3.368 & 73 & 3 \\
\hline Villar del Río & 12.703 & 159 & 13 \\
\hline Vizmanos & 2.431 & 27 & 2 \\
\hline Las Aldehuelas & 3.788 & 75 & 5 \\
\hline Total & 27.620 & 457 & 28 \\
\hline \multicolumn{4}{|l|}{ Tierra de San Pedro (alto valle del Linares) } \\
\hline Oncala & 3.992 & 94 & 4 \\
\hline San Pedro Manrique & 17.620 & 618 & 18 \\
\hline Total & 21.612 & 712 & 22 \\
\hline TOTAL SIETE MUNICIPIOS & 49.232 & 1.169 & 50 \\
\hline
\end{tabular}

Al igual que en el resto de la comarca, el poblamiento del área es multinuclear: pese al extremadamente bajo volumen demográfico, en las tierras de Yanguas y San Pedro se asientan cincuenta pueblos de tamaño reducido, de modo que todos los municipios actuales incluyen en su término varias entidades de población identificadas y recogidas en el nomenclátor (hasta dieciocho en uno de ellos). A mediados del siglo xx estos pueblos serranos salpicados por el territorio con notable densidad (uno cada $9,8 \mathrm{~km}^{2}$, por término medio) estaban habitados y vivos y la mitad de ellos contaba con más de un centenar de habitantes, incluyendo la villa de San Pedro Manrique, que se aproximaba al millar (965 habitantes); por entonces el $51 \%$ de la población de los altos valles del Cidacos y el Linares área residía en once pueblos de más de doscientos habitantes. Sin embargo, en 1970, tras veinte años de intensísima emigración, los núcleos de más de cien habitantes eran ya claramente minoritarios (el $20 \%$ del total) y sólo San Pedro Manrique mantenía más de quinientos residentes; en esa fecha la quinta parte de los asentamientos se habían quedado vacíos y la población residente en núcleos de más de 200 habitantes (solamente una) apenas pasaba del $25 \%$. Y en la actualidad, como consecuencia del mantenimiento de las pérdidas demográficas a lo largo de más de cuatro décadas, dieciocho pueblos (el $36 \%$ del total) se encuentran oficialmente vacíos y otros quince (el $30 \%$ ) se encuentran de hecho en la misma situación, ya que cuentan con menos de diez habitantes; sólo dos núcleos (las cabeceras de las dos viejas comunidades de villa y tierra) conservan más de un centenar de residentes y las personas que viven en el único asentamiento de más de doscientos habitantes representan el $27 \%$ del total.

Se aprecia, pues, cómo en los últimos sesenta y cinco años los efectivos demográficos de los dos valles se han reducido en un $83 \%$, pero lo más destacado e indicador de la rapidez y la concentración temporal del proceso de abandono es que sólo en el periodo intercensal 19601970 se marcharon más de la mitad de los habitantes, que pasaron de 5.466 a 2.541. Entre el último de los años citados y el año 2000 la población se redujo de nuevo a menos de la mitad de esta cifra (de 2.541 a 1.131 habitantes). En lo que va de siglo XxI el vaciamiento parece haber tocado fondo y el número de residentes censados se ha mantenido entre los 1.100 y los 1.200 .

La despoblación extrema y el alto número de núcleos despoblados constituyen no sólo una de las características básicas del territorio de las Tierras de Yanguas y de San Pedro (y de todo el conjunto de las Tierras Altas), sino también uno de los rasgos fundamentales de su paisaje, que lo diferencian dentro del conjunto de la provincia de Soria. Y hay que resaltar que esta diferenciación de las Tierras Altas como espacio vacío y como ámbito marcado por los paisajes de la despoblación, dentro incluso del marco provincial más desfavorecido demográficamente de toda España, es un hecho reciente y resultado de la emigración masiva de sus habitantes en las últimas cinco décadas del siglo $\mathrm{xx}$, a la que se acaba de hacer referencia. Hasta los años centrales del pasado siglo la densidad de población de la Sierra y de cualquiera de sus sectores (14-18 habs. $/ \mathrm{km}^{2}$ ) era análoga o ligeramente superior a la media de la provincia, pero a partir de enton- 


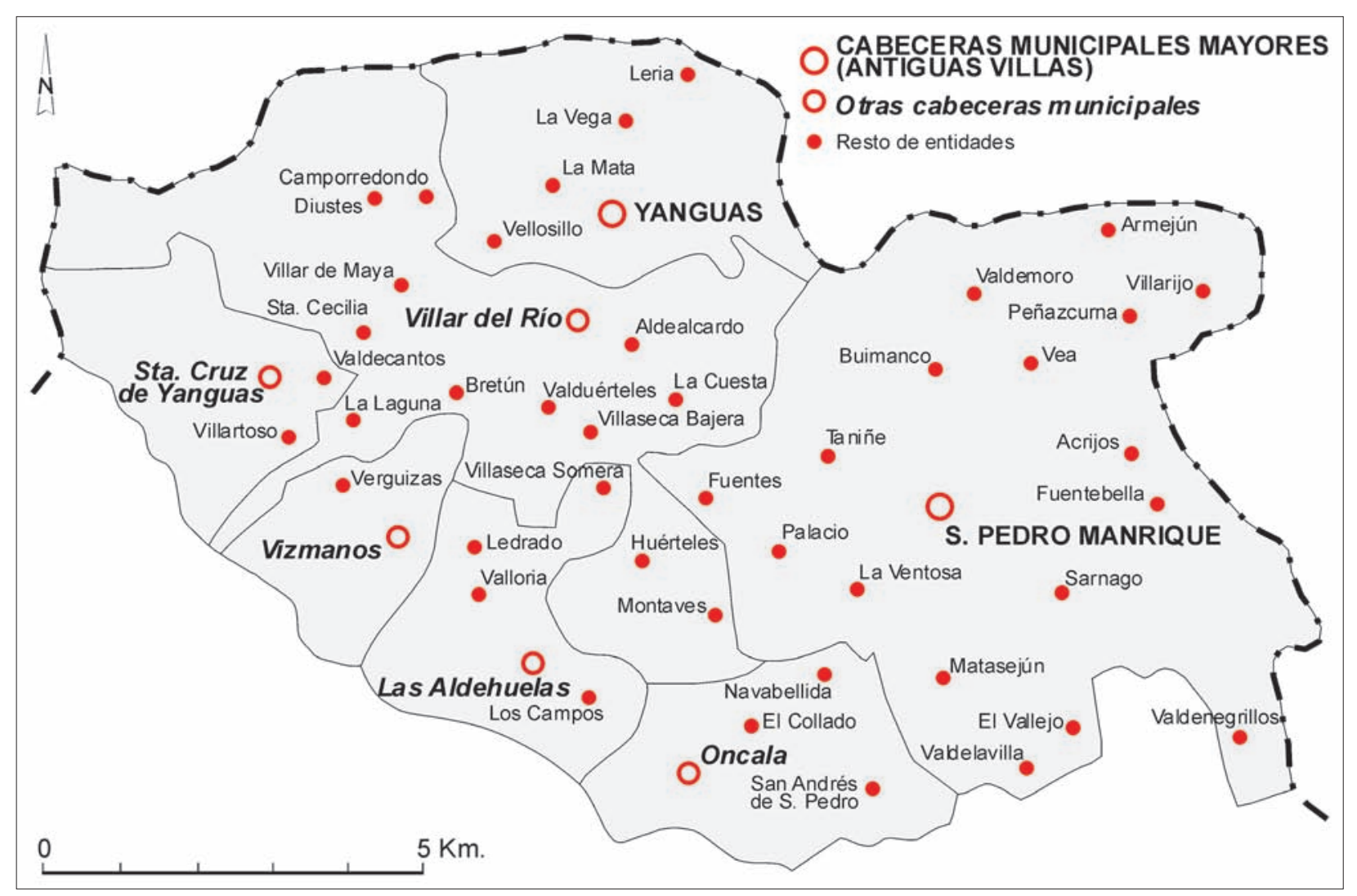

FIg. 4. Organización municipal y localización de los asentamientos en las Tierras Altas de Yanguas y de San Pedro Manrique.

ces la disminución de ésta ha tenido un ritmo mucho más acusado que el registrado en el resto de Soria, de modo que desde el año 2000 no llega a 3 habs. $/ \mathrm{km}^{2}$ (la tercera parte de la ya exigua media provincial).

Las pérdidas demográficas masivas y el abandono de los hogares han afectado y se manifiestan en todo el territorio analizado, pero no han afectado de la misma manera a los dos valles que lo constituyen. En el valle del Cidacos la reducción de la población ha sido mayor y más prolongada, pero ha sido menor el número de pueblos que han llegado al despoblamiento total; en el valle del Linares, por su parte, las pérdidas han sido algo menores y ya se han estabilizado en los últimos años, pero el abandono total ha afectado antes y a un número significativamente mayor de entidades de población.

Las tierras de Yanguas y San Pedro, de forma aún más marcada que el conjunto de las Tierras Altas, constituyen pues un espacio en el que la densidad de población ha descendido hasta unos niveles tan excepcionalmente bajos y el abandono ha afectado a un número tan alto de pueblos que ha llegado estar prácticamente vacío. Ello ha ido acompañado de un fuerte cambio en la estructura demográfica, cuyos rasgos fundamentales son en la actualidad un elevado porcentaje de personas mayores (35-40\% de mayores de 65 años), un escasísimo porcentaje de niños y jóvenes (8-10\% de menores de 25 años) y una tasa de actividad muy reducida (sólo el $22 \%$ de los pobladores se reconocen como económicamente activos). Estos indicadores resaltan incluso en una provincia tan envejecida como la de Soria, en el conjunto de la cual la población mayor de 65 años representa el $25 \%$ y la menor de 25 años el $22 \%$, al tiempo que la tasa de actividad se aproxima al 35 \% (Bachiller Martínez, 2008; Martín Jiménez, 2008).

Esta despoblación masiva iniciada a mediados de siglo xx y significativamente acelerada (e incluso oficialmente fomentada) en los años sesenta y setenta, junto con el correlativo envejecimiento y el abandono de los aprovechamientos y usos del suelo e incluso de los edificios, constituye uno de los aspectos más importantes para el entendimiento de los caracteres, la organización y la dinámica de un territorio donde los núcleos de población casi vacíos y los despoblados, mejor o peor conservados 


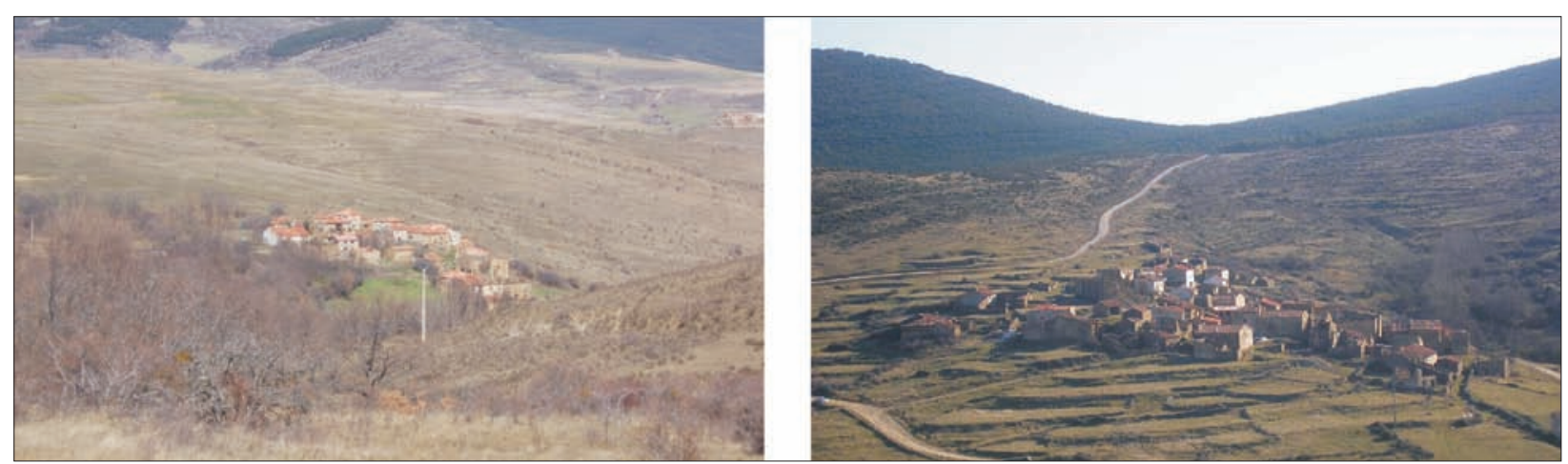

FIG. 5. Asentamientos despoblados: a la izquierda, Verguizas (dos habitantes), en la Tierra de Yanguas; a la derecha, Sarnago (un habitante), en la Tierra de San Pedro.

según la fecha de la emigración de sus vecinos y de su grado de abandono por parte de éstos y de sus descendientes, son numerosos y constituyen un elemento básico de su paisaje (Córdoba Largo, 1983; Sanz Sánchez, 2001; Goig Soler, 2002).

\section{ORIGEN Y EVOLUCIÓN HISTÓRICA DE LA POBLACIÓN, DE LA ORGANIZACIÓN DEL TERRITORIO Y DEL TIPO DE POBLAMIENTO EN LAS TIERRAS ALTAS DE YANGUAS Y DE SAN PEDRO}

El hecho de que la citada emigración masiva haya tenido unas consecuencias tan marcadas y peculiares en el poblamiento, implicando el vaciamiento extremo de gran parte de los núcleos y la aparición de un alto número de despoblados, se relaciona con la organización medieval del área y su evolución histórica vinculada durante siglos a la trashumancia organizada y regida desde 1489 hasta 1836 por la Real Mesta de Ganaderos (Klein, 1994; Anes y García Sáinz, 1994; Diago Hernando, 2002).

La instalación de una población estable en el territorio hoy denominado Tierras Altas se inicia en el siglo XII y se lleva a cabo mediante la fundación de villas, entre ellas la de Soria, a cada una de las cuales se adscribe una «tierra» en la que, para su colonización y la explotación de sus recursos, se asientan «lugares» $\mathrm{y}$ «aldeas»; en los casos en que la superficie adscrita es grande, se divide desde el punto de vista administrativo en «sexmos» o distritos compuestos por el territorio explotado por grupos de estas aldeas. La más importante y extensa de estas «comunidades de villa y tierra» es la de Soria, que se consolida en 1256 gracias a la concesión de un fuero propio por parte del rey Alfonso X y se organiza desde entonces en cinco sexmos (a dos de los cuales, los de Tera y San Juan, pertenecen los sectores suroccidentales de las Tierras Altas vertientes al Duero) (Ruiz, 2001).

Los sectores nororientales vertientes al Ebro, por su parte, se dividen entonces entre cuatro comunidades de menor rango y extensión, encabezadas por las villas de Yanguas, San Pedro Manrique, Magaña y Ágreda (las tres primeras de las cuales se emplazan dentro del área y la última en sus proximidades). Como ya se ha señalado, a la comunidad de villa y tierra de Yanguas queda adscrita la parte del territorio drenada por el río Cidacos y a la comunidad de villa y tierra de San Pedro, el valle del Linares. Esta forma «comunitaria» de ocupación y administración del territorio estuvo vigente hasta, al menos, los últimos años de Edad Media y ha dejado huellas todavía significativas en la estructura y en el paisaje del área, en especial el tipo de poblamiento compuesto por una alta densidad de núcleos habitados de pequeña dimensión que la caracteriza.

Las comunidades citadas controlaron toda la Sierra (y concretamente las tierras de Yanguas y San Pedro) sin sufrir apenas interferencia por parte del poder señorial a lo largo de los siglos XIII, XIV y gran parte del xv, estableciendo en ella un sistema de uso en el que se combinaban el aprovechamiento de los montes, la agricultura de subsistencia y la ganadería, principalmente ovina. Esta última actividad, de importancia creciente como consecuencia de la calidad de los pastos de verano obtenidos en las laderas y cumbres que iban siendo deforestadas, era inicialmente autóctona y estante; y las villas (que procuraban por todos los medios evitar la entrada cada vez más frecuente de «rebaños estraños») se esforzaban por limitar el área de pastoreo creando dehesas donde se conservase la vegetación forestal y pudiese ser aprovechada por los vecinos de cada aldea (Asenjo González, 1999). 
CuAdro II. Evolución demográfica de los núcleos de población de las Tierras Altas de Yanguas y San Pedro de 1950 a 2014

\begin{tabular}{|c|c|c|c|c|c|}
\hline \multirow[b]{2}{*}{ Tierra de Yanguas (alto valle del Cidacos) } & 1950 & 1960 & 1970 & 2000 & 2014 \\
\hline & \multirow[b]{2}{*}{399} & \multirow[b]{2}{*}{324} & \multirow[b]{2}{*}{171} & \multirow[b]{2}{*}{136} & \multirow[b]{2}{*}{119} \\
\hline YANGUAS & & & & & \\
\hline Leria & 18 & 10 & 0 & 0 & 0 \\
\hline La Mata & 28 & 19 & 0 & 0 & 0 \\
\hline La Vega & 129 & 102 & 0 & 0 & 4 \\
\hline Vellosillo & 30 & 32 & 37 & 0 & 0 \\
\hline Santa CRUZ de Yanguas & 254 & 232 & 70 & 41 & 49 \\
\hline Valdecantos & 17 & 11 & 3 & 0 & 0 \\
\hline Villartoso & 40 & 37 & 35 & 20 & 24 \\
\hline VILLAR DEL RÍo & 242 & 127 & 141 & 66 & 59 \\
\hline Aldealcardo & 13 & 14 & 25 & 0 & 0 \\
\hline Bretún & 222 & 257 & 64 & 13 & 16 \\
\hline Camporredondo & 33 & 6 & 6 & 2 & 1 \\
\hline La Cuesta & 146 & 146 & 45 & 1 & 7 \\
\hline Diustes & 194 & 178 & 44 & 3 & 5 \\
\hline La Laguna & 25 & 14 & 16 & 3 & 4 \\
\hline Huérteles & 235 & 327 & 126 & 60 & 55 \\
\hline Montaves & 67 & 33 & 36 & 14 & 5 \\
\hline Santa Cecilia & 78 & 27 & 28 & 5 & 3 \\
\hline Valduérteles & 60 & 22 & 22 & 5 & 2 \\
\hline Villar de Maya & 147 & 14 & 11 & 8 & 2 \\
\hline Villaseca Bajera & 25 & 1 & 0 & 0 & 0 \\
\hline Vizmanos & 208 & 131 & 96 & 35 & 25 \\
\hline Verguizas & 30 & 30 & 32 & 6 & 2 \\
\hline Las Aldehuelas & 120 & 107 & 80 & 35 & 19 \\
\hline Los Campos & 123 & 114 & 79 & 36 & 24 \\
\hline Ledrado & 30 & 30 & 19 & 7 & 6 \\
\hline Valloria & 118 & 102 & 87 & 33 & 19 \\
\hline Villaseca Somera & 33 & 31 & 11 & 9 & 7 \\
\hline Total & 3.064 & 2.478 & 1.284 & 538 & 457 \\
\hline \multicolumn{6}{|c|}{ Tierra de San Pedro (alto valle del Linares) } \\
\hline ONCALA & 239 & 175 & 115 & 70 & 51 \\
\hline El Collado & 130 & 147 & 24 & 4 & 20 \\
\hline Navabellida & 79 & 20 & 15 & 7 & 4 \\
\hline San Andrés de San Pedro & 123 & 112 & 68 & 25 & 19 \\
\hline San Pedro ManriQue & 965 & 693 & 648 & 446 & 575 \\
\hline Acrijos & 149 & 84 & 6 & 0 & 0 \\
\hline Armejún & 135 & 96 & 4 & 0 & 0 \\
\hline Buimanco & 91 & 56 & 0 & 0 & 0 \\
\hline Fuentebella & 142 & 126 & 8 & 0 & 0 \\
\hline Fuentes de San Pedro & 88 & 43 & 33 & 3 & 4 \\
\hline Matasejún & 167 & 180 & 85 & 11 & 14 \\
\hline Palacio de San Pedro & 90 & 40 & 47 & 14 & 10 \\
\hline Peñazcurna & 36 & 16 & 0 & 0 & 0 \\
\hline Sarnago & 311 & 371 & 34 & 0 & 1 \\
\hline Taniñe & 109 & 164 & 22 & 1 & 2 \\
\hline Valdelavilla & 33 & 18 & 0 & 0 & 0 \\
\hline Valdemoro de San Pedro & 153 & 43 & 0 & 0 & 0 \\
\hline Valdenegrillos & 88 & 16 & 35 & 2 & 0 \\
\hline El Vallejo & 44 & 20 & 0 & 0 & 0 \\
\hline Vea & 216 & 157 & 0 & 0 & 0 \\
\hline La Ventosa & 175 & 250 & 94 & 10 & 12 \\
\hline Villarijo & 206 & 161 & 19 & 0 & 0 \\
\hline Total & 3.769 & 2.988 & 1.257 & 593 & 712 \\
\hline TOTAL CONJUNTO & 6.833 & 5.466 & 2.541 & 1.131 & 1.169 \\
\hline
\end{tabular}




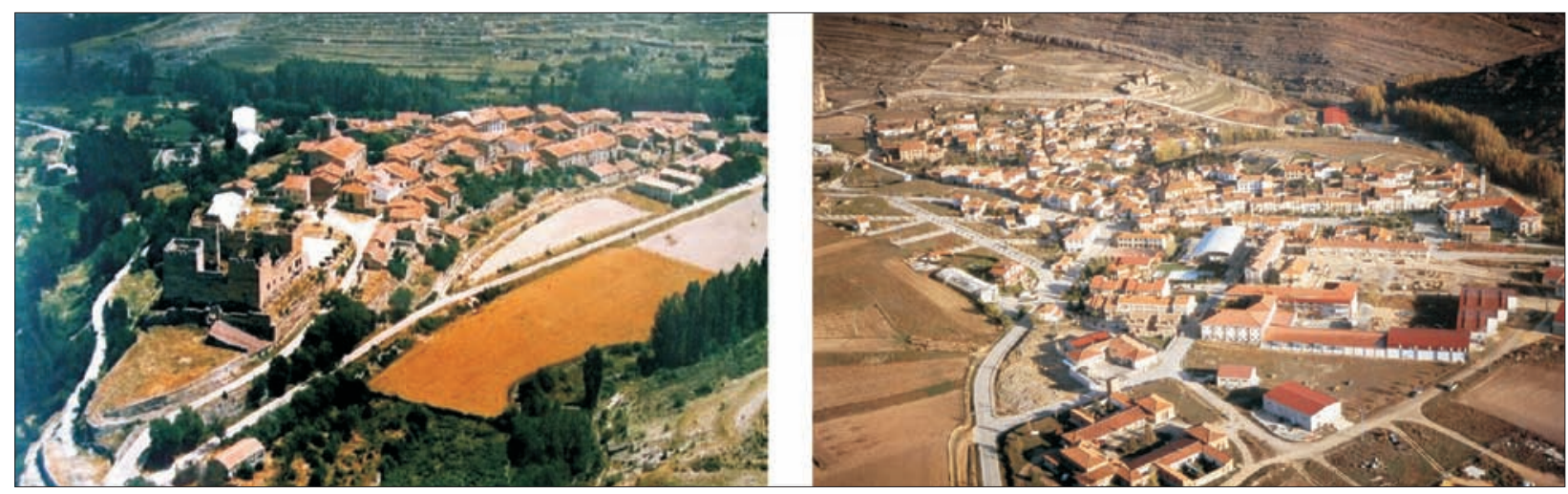

FIG. 6. Vista actual de las antiguas villas de Yanguas (izquierda) y San Pedro Manrique (derecha), cabeceras de las comunidades de villa y tierra históricas del mismo nombre.

En el último tercio del siglo xv, coincidiendo con los reinados de Enrique IV y de los Reyes Católicos, se producen unos cambios fundamentales que afectan decisivamente al gobierno y al funcionamiento socioeconómico de las Tierras Altas. El primero de ellos es la supresión en la práctica de las comunidades de villa y tierra y su entrega a la nobleza como «tierras de señorío», de la que sólo se libra plenamente la muy poderosa comunidad de Soria. El segundo, derivado en gran parte del anterior, es el paso a actividad principal de la ganadería lanar (que se hace trashumante y se integra en un sistema económico de escala nacional e incluso europea) y la incorporación plena de los nuevos señores a la Real Cabaña de la Mesta para aprovechar el privilegio de 1489 por el que la Corona concede a los ganados trashumantes el derecho a «transitar, pacer y beber en todas las tierras, salvo la de labor, viña, huerta, prado de siega y dehesa boyal» (Klein, 1994).

Así, la Tierra de Yanguas se incorpora al señorío de Los Cameros, perteneciente a los condes de Aguilar, y la Tierra de San Pedro pasa a formar parte de los dominios de los duques de Arcos. Estos nuevos poderes nobiliarios, junto con los que han adquirido el dominio de las otras comunidades (los marqueses de Vadillo y los duques de Alba, entre otros), constituyen dentro de la Mesta la «cuadrilla de Soria»y abren las Tierras Altas a los rebaños trashumantes de ovejas de raza merina productoras de «lana fina». Al tiempo transforman a una parte sustancial de sus habitantes varones en pastores que se desplazan todos los años a Extremadura, Andalucía o el sur de Castilla la Nueva y permanecen muchos meses (desde octubre de cada año hasta junio del año siguiente) muy lejos de sus lugares de residencia, dejando durante el crudo invierno a las mujeres y a los niños en las aldeas y los lugares, cuyos nombres son (en el área de estudio) los de los cincuenta pueblos y despoblados que en la actualidad aún en él se reconocen (Río, 1828; Alcaide Jiménez, 2000).

Durante los siglos XVI, XVII y XVIII todo el territorio de las entonces denominadas «sierra de Cameros» $\mathrm{y}$ «sierra de San Pedro» queda bajo el control de la Mesta, que controla y rige de hecho la explotación de la tierra para mantenerla como área privilegiada de pastos de verano y punto de partida de sus más importantes cañadas. Desempeñan en ello un papel fundamental las familias nobles y las instituciones dueñas de los ganados ovinos y de los lavaderos de lana, así como los alcaldes entregadores, los procuradores y el resto de los funcionarios nombrados por la Real Cabaña. A lo largo de este periodo, en el que las cabezas de lanar merino que entran y salen del área cada temporada se cuentan por cientos de miles, se produce una reducción extrema del área correspondiente a montes y baldíos, que sólo se consideran guarida de animales dañinos para el ganado. Es en estos siglos en los que se consuma el desmantelamiento de los bosques originarios de frondosas para ampliar al máximo la superficie de pastizal y las Tierras Altas adquieren el paisaje de montaña desarbolada que las caracteriza, al tiempo que se establece la vinculación de éstas a la ganadería lanar, a la trashumancia y a la Mesta (Manrique de Lara, 1970; Pérez Guinea, 1982).

De acuerdo con la información recogida en el catastro del marqués de la Ensenada (1752), a mediados del siglo XviII (que se puede considerar el momento de mayor consolidación del sistema ganadero trashumante) aprovechaban los pastos de verano del territorio estudiado (Tierras de Yanguas y San Pedro) poco menos de cien mil ovejas productoras de lana fina y en él tenían re- 
CuAdro III. Organización del territorio de las tierras de Yanguas y de San Pedro a comienzos del siglo XVI (vigente hasta la desvinculación de los señoríos en 1829)

Comunidad de Villa y Tierra de Yanguas/ señorío de Cameros (condado de Aguilar)

\section{Villa: Yanguas.}

Aldeas: Aldealcardo, Las Aldehuelas, Bretún, Camporredondo, Los Campos, La Cuesta, Diustes, La Laguna, Ledrado, Leria, La Mata, Santa Cecilia, Santa Cruz, Valdecantos, Valduérteles, Valoria, La Vega, Vellosillo, Verguizas, Villar de Maya, Villar del Río, Villartoso, Villaseca Somera, Villaseca Bajera, Vizmanos.

Comunidad de Villa y Tierra de San Pedro Manrique/ dominios del duque de Arcos

\section{Villa: San Pedro Manrique.}

Sexmos

Sexmo de San Pedro (aldeas: Sarnago, Matasejún, Valdeprado, Valdenegrillos, El Vallejo, Valdelavilla).

Sexmo de Huérteles (aldeas: Huérteles, Palacio, Las Fuentes, Montabes, Taniñe, La Ventosa).

Sexmo de Oncala (aldeas: Oncala, El Collado, San Andrés, Navabellida).

Sexmo de Vea o de Montes (aldeas: Vea, Peñazcurna, Villarijo, Armejún, Valdemoro, Buimanco, Acrijos, Fuentebella).

gistrada su residencia alrededor de 8.124 personas $(16,9$ habs. $/ \mathrm{km}^{2}$ ) distribuidas en las cincuenta poblaciones antes enumeradas (dos villas y 48 aldeas), el $65 \%$ de las cuales contaban con más de cien habitantes. Las villas cabecera de las dos comunidades, Yanguas y San Pedro Manrique, contaban entonces con 566 y 1.107 habitantes, respectivamente. Sin embargo, una parte mayoritaria de la población masculina tenía como ocupación el pastoreo en sus diferentes niveles (mayoral, rabadán, ayudador, sobrado, zagal) y, como se ha dicho, permanecía gran parte del año fuera de la Sierra cuidando los rebaños de ovejas en las dehesas de Andalucía o Extremadura; también un número significativo de varones (conocidos como «cagarraches») se desplazaba en el invierno para trabajar en los molinos de aceite de estas regiones del sur. Y dentro de la población que permanecía en la zona todo el año se encontraban también muchas personas dedicadas a labores relacionadas con la producción de lana fina: esquiladores, empleados de lavaderos de lana y, sobre todo, cardadores («pelaires»). En comparación con esta actividad ganadera, muy bien organizada y de alta rentabilidad, basada en el aprovechamiento de unos pastos de buena calidad disponibles en los meses del verano, cuando escaseaban en otros lugares, la agricultura se limitaba a la producción de lo necesario para un abastecimiento básico de cereales y verduras y la explotación

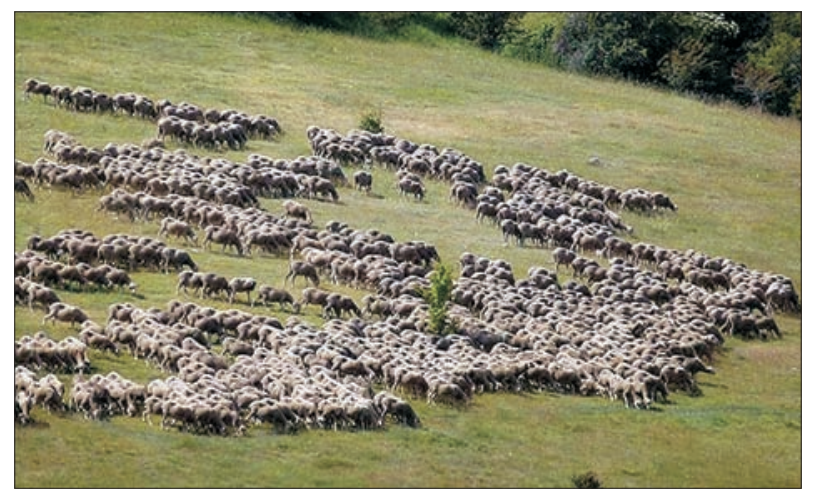

FIg. 7. Pastizales de verano en la Tierra de Yanguas, aún aprovechados por algunos rebaños de ganado lanar.

forestal se reducía al aprovechamiento de las pequeñas dehesas comunales de roble, encina, acebo o haya (con frecuencia cercadas por muros de piedra) reservadas para aprovisionar a los pueblos de madera y leña (Río, 1828; Pérez Romero, 1995).

Cuando, en el primer tercio del XIX, los fundamentos del sistema económico en que se encuadran este tipo de aprovechamiento y esta forma de vida entran en crisis de forma acelerada debido a la caída del precio de la lana en los mercados internacionales, los altos valles sorianos del Cidacos y el Linares (hoy vacíos y prácticamente inactivos) habían alcanzado su máximo nivel de ocupación, nunca recuperado en el futuro: en 1824 residían en ellos 9.224 personas $\left(18,8\right.$ habs. $\left./ \mathrm{km}^{2}\right)$, la villa de San Pedro Manrique tenía 1.407 habitantes y la de Yanguas, 656, al tiempo que un número significativo de aldeas, como Santa Cruz de Yanguas, Villar del Río, Huérteles, Vizmanos, Oncala, San Andrés o Matasejún, sobrepasaban los doscientos cincuenta habitantes.

Poco después son abolidos los señoríos (entre ellos el condado de Aguilar y el ducado de Arcos) y, en 1836, desaparece oficialmente la Real Mesta de Ganaderos, incluida la poderosa cuadrilla de Soria. Al tiempo, la organización histórica del territorio, fundada en comunidades de villa y tierra sometidas al dominio señorial, es sustituida por la articulada en grandes partidos judiciales y pequeños municipios que estuvo vigente hasta mediados del siglo xx y de la que, mediante fusión, deriva la actual estructura administrativa. De este modo, al igual que el resto de la Sierra vertiente al Ebro, las tierras de Yanguas y San Pedro quedan encuadradas en el partido judicial de Ágreda y sus habitantes, después de vivir desde tiempo inmemorial en régimen de mancomunidad, ven dividido su territorio en 42 términos municipales (prácticamente uno por entidad de población) (Alcaide Jiménez, 2000). 
E R Í A

CuAdRo IV . Evolución demográfica de los núcleos de población de las Tierras Altas de Yanguas y San Pedro de 1752 a 1930

\begin{tabular}{|c|c|c|c|c|c|c|}
\hline & 1752 & 1824 & 1845 & 1860 & 1900 & 1930 \\
\hline \multicolumn{7}{|l|}{ Alto valle del Cidacos } \\
\hline YANGUAS & 566 & 656 & 650 & 591 & 554 & 437 \\
\hline Leria & 73 & 83 & 102 & 204 & 45 & 88 \\
\hline La Mata & 68 & 65 & 64 & 102 & 48 & 56 \\
\hline La Vega & 87 & 85 & 90 & 112 & 240 & 234 \\
\hline Vellosillo & 45 & 52 & 48 & 55 & 54 & 92 \\
\hline SANTA CRuZ De Yanguas & 273 & 275 & 198 & 200 & 228 & 238 \\
\hline Valdecantos & 90 & 103 & 95 & 78 & 22 & 48 \\
\hline Villartoso & 32 & 36 & 30 & 33 & 45 & 71 \\
\hline VILLAR DEL Río & 285 & 283 & 244 & 340 & 310 & 350 \\
\hline Aldealcardo & 110 & 115 & 106 & 54 & 24 & 60 \\
\hline Bretún & 115 & 128 & 140 & 304 & 275 & 308 \\
\hline Camporredondo & 63 & 70 & 78 & 85 & 80 & 80 \\
\hline La Cuesta & 143 & 145 & 134 & 266 & 164 & 126 \\
\hline Diustes & 138 & 175 & 172 & 236 & 234 & 217 \\
\hline La Laguna & 34 & 35 & 30 & 25 & 24 & 24 \\
\hline Huérteles & 181 & 276 & 304 & 346 & 231 & 263 \\
\hline Montaves & 49 & 47 & 60 & 65 & 67 & 55 \\
\hline Santa Cecilia & 160 & 125 & 90 & 87 & 85 & 107 \\
\hline Valduérteles & 117 & 108 & 60 & 74 & 72 & 60 \\
\hline Villar de Maya & 139 & 142 & 136 & 196 & 163 & 238 \\
\hline Villaseca Bajera & 53 & 50 & 41 & 45 & 27 & 38 \\
\hline VIZMANOS & 215 & 282 & 150 & 192 & 231 & 263 \\
\hline Verguizas & 105 & 83 & 58 & 61 & 35 & 83 \\
\hline Las Aldehuelas & 83 & 96 & 95 & 180 & 117 & 114 \\
\hline Los Campos & 110 & 107 & 115 & 120 & 116 & 95 \\
\hline Ledrado & 68 & 64 & 42 & 43 & 45 & 52 \\
\hline Valloria & 126 & 130 & 128 & 119 & 114 & 120 \\
\hline Villaseca Somera & 88 & 91 & 67 & 54 & 46 & 41 \\
\hline Total & 3.616 & 3.907 & 3.327 & 4.267 & 3.682 & 3.958 \\
\hline \multicolumn{7}{|l|}{ Alto VALLE DEL LinARES } \\
\hline$\overline{\text { ONCALA }}$ & 202 & 325 & 250 & 235 & 246 & 295 \\
\hline El Collado & 107 & 184 & 120 & 121 & 104 & 134 \\
\hline Navabellida & 78 & 90 & 82 & 80 & 74 & 82 \\
\hline San Andrés de San Pedro & 195 & 395 & 210 & 259 & 219 & 202 \\
\hline SAN PEDRo MANRIQUe & 1148 & 1407 & 1550 & 748 & 921 & 861 \\
\hline Acrijos & 127 & 195 & 170 & 174 & 180 & 184 \\
\hline Armejún & 176 & 180 & 137 & 163 & 176 & 166 \\
\hline Buimanco & 114 & 138 & 196 & 213 & 155 & 154 \\
\hline Fuentebella & 140 & 176 & 158 & 156 & 202 & 193 \\
\hline Fuentes de San Pedro & 91 & 85 & 90 & 93 & 92 & 90 \\
\hline Matasejún & 271 & 370 & 316 & 294 & 180 & 175 \\
\hline Palacio de San Pedro & 147 & 95 & 102 & 105 & 102 & 78 \\
\hline Peñazcurna & 34 & 63 & 24 & 30 & 35 & 33 \\
\hline Sarnago & 224 & 225 & 140 & 177 & 218 & 191 \\
\hline Taniñe & 414 & 276 & 250 & 376 & 124 & 150 \\
\hline Valdelavilla & 52 & 71 & 36 & 42 & 40 & 35 \\
\hline Valdemoro de San Pedro & 136 & 241 & 148 & 144 & 159 & 143 \\
\hline Valdenegrillos & 113 & 124 & 71 & 75 & 83 & 163 \\
\hline El Vallejo & 67 & 69 & 42 & 52 & 45 & 59 \\
\hline Vea & 166 & 200 & 152 & 196 & 196 & 182 \\
\hline La Ventosa & 248 & 155 & 300 & 297 & 222 & 281 \\
\hline Villarijo & 258 & 253 & 130 & 224 & 293 & 253 \\
\hline Total & 4.508 & 5.317 & 4.674 & 4.254 & 4.066 & 4.379 \\
\hline TOTAL CONJUNTO & 8.124 & 9.224 & 8.001 & 8.521 & 7.748 & 8.337 \\
\hline
\end{tabular}


Desde el punto de vista económico, en las Tierras Altas la alternativa al monocultivo secular de los pastos de verano consistió en mantener en lo posible la actividad ganadera lanar e incluso el sistema trashumante, asumiendo los pastores locales (además del cuidado) la propiedad de los rebaños y reduciendo el volumen de éstos, así como la superficie dedicada a su alimentación. En los valles del Cidacos y el Linares, las tierras así liberadas, incluso las emplazadas en laderas de fuerte pendiente o ámbitos de suelo poco productivo, fueron puestas en cultivo para alimentar una población que se mantuvo durante los siguientes cien años (hasta 1930) en torno a los ocho mil habitantes (15-17 habs. $\left./ \mathrm{km}^{2}\right)$. Se pudo así mantener, con crecientes dificultades, la viabilidad económica de este sector de la Sierra, a costa de un empobrecimiento extremo de sus pobladores y de una emigración de volumen moderado (primero estacional y después definitiva) a las regiones de destino de la trashumancia tradicional, sobre todo a Andalucía. De esta época, en la que las cabezas de ganado ovino se contaban ya por decenas de miles (incluyendo un número apreciable de cabezas estantes de raza churra), los municipios con ganado trashumante reducían su número hasta hacerse minoritarios y una parte del viaje de las merinas a los pastos de invierno se iba realizando en tren, data la proliferación de parcelas («piezas») abancaladas para el cultivo de cereales que, fuera ya de todo uso y cubiertas de eriales o matorrales, se observan actualmente en multitud de vertientes y laderas de las antiguas tierras de Yanguas y San Pedro (Avelino Hernández, 1982; Goig Soler y Goig Soler, 1996; Abel Hernández, 2008, 2010 y 2011a).

Pronto se pone de manifiesto que la crisis de los usos ganaderos tradicionales se acelera y los nuevos cultivos no dan un rendimiento suficiente, aunque la población, en una situación de creciente precariedad económica, no disminuye en principio significativamente, manteniéndose por encima de los 5.500 habitantes (11-12 habs. $\left./ \mathrm{km}^{2}\right)$. Pero en los años sesenta y setenta los escasos recursos producidos por una ganadería reducida al mínimo y una agricultura de secano marginal y minifundista hacen ya inviable el mantenimiento de este volumen demográfico, al tiempo que la administración favorece, e incluso impone, políticas que pretenden cambiar el sistema de aprovechamiento del suelo vigente por otro más eficaz y presuntamente más acorde con las limitadas potencialidades naturales del área (Hernández, 2010; Hernández, 2011b). Estas políticas son la repoblación forestal, para cuya realización el Patrimonio Forestal del Estado compra o expropia sus tierras nada o escasamente rentables a los habitantes de las pueblos, y obliga a reorganizar el terrazgo aceptablemente productivo (concentrando las múltiples parcelas en pocos campos de extensión adecuada para el uso de maquinaria agrícola). El resultado de estas acciones, que se concretaron en lo que en Soria se denominó Operación San Pedro Manrique, auspiciada por la FAO y el Banco Mundial, planificada por el Ministerio de Agricultura e impulsada decididamente desde 1964-1965 por el Gobierno Civil de la provincia, es la emigración masiva y rapidísima y el abandono definitivo de los pueblos, a lo que ya se ha hecho referencia al tratar de la población y el poblamiento (Monge, 1964 y 1965; Martín Jiménez, 2004; Bachiller Martínez, 2008). La consecuencia de todo es que hoy las tierras de Yanguas y San Pedro, con poco más de 1.100 habitantes $\left(2,4\right.$ habs. $\left.\mathrm{km}^{2}\right)$ y casi la mitad de su superficie calificada como improductiva, lo mismo que el conjunto de las Tierras Altas sorianas, sean el paradigma de la despoblación y el abandono de las áreas de montaña del interior de España (Sanz Sánchez, 2001; Goig Soler, 2002; Martín Jiménez, 2008).

\section{LOS DESPOBLADOS DE LAS TIERRAS ALTAS DE YANGUAS Y DE SAN PEDRO: SIGNIFICADO TERRITORIAL Y PAISAJÍSTICO DE LOS PUEBLOS DESOCUPADOS, ABANDONADOS Y EN RUINAS}

Como consecuencia de la evolución histórica y de las circunstancias actuales que en sus líneas básicas se acaban de exponer, en el área estudiada sólo existe hoy un número muy reducido de núcleos de población en el sentido que se da oficialmente a esta denominación en el organismo que se encarga en España de los registros estadísticos. De acuerdo con lo establecido por el Instituto Nacional de Estadística, sólo deben considerarse núcleos de población las «entidades que cuentan con más de 50 habitantes y en las que la mayor parte de las construcciones y de las calles se mantienen en buen estado de conservación». Aplicando la definición de forma laxa, estas condiciones sólo las cumplen en las Tierras Altas de Yanguas y de San Pedro seis pueblos: San Pedro Manrique (con más de quinientos habitantes), Yanguas (con algo más de cien habitantes) y Santa Cruz de Yanguas, Villar del Río, Huérteles y Oncala (que cuentan con alrededor de cincuenta habitantes); en esta media docena de «pueblos habitados» tiene su residencia el 77,7\% de la población (908 habitantes). Los restantes 44 pueblos que salpican los valles sorianos del Cidacos y el Linares, entre los que se distribuye el 22,3\% (261 habitantes), deberían en consecuencia ser considerados desde el punto de vista demográfico «despoblados». 


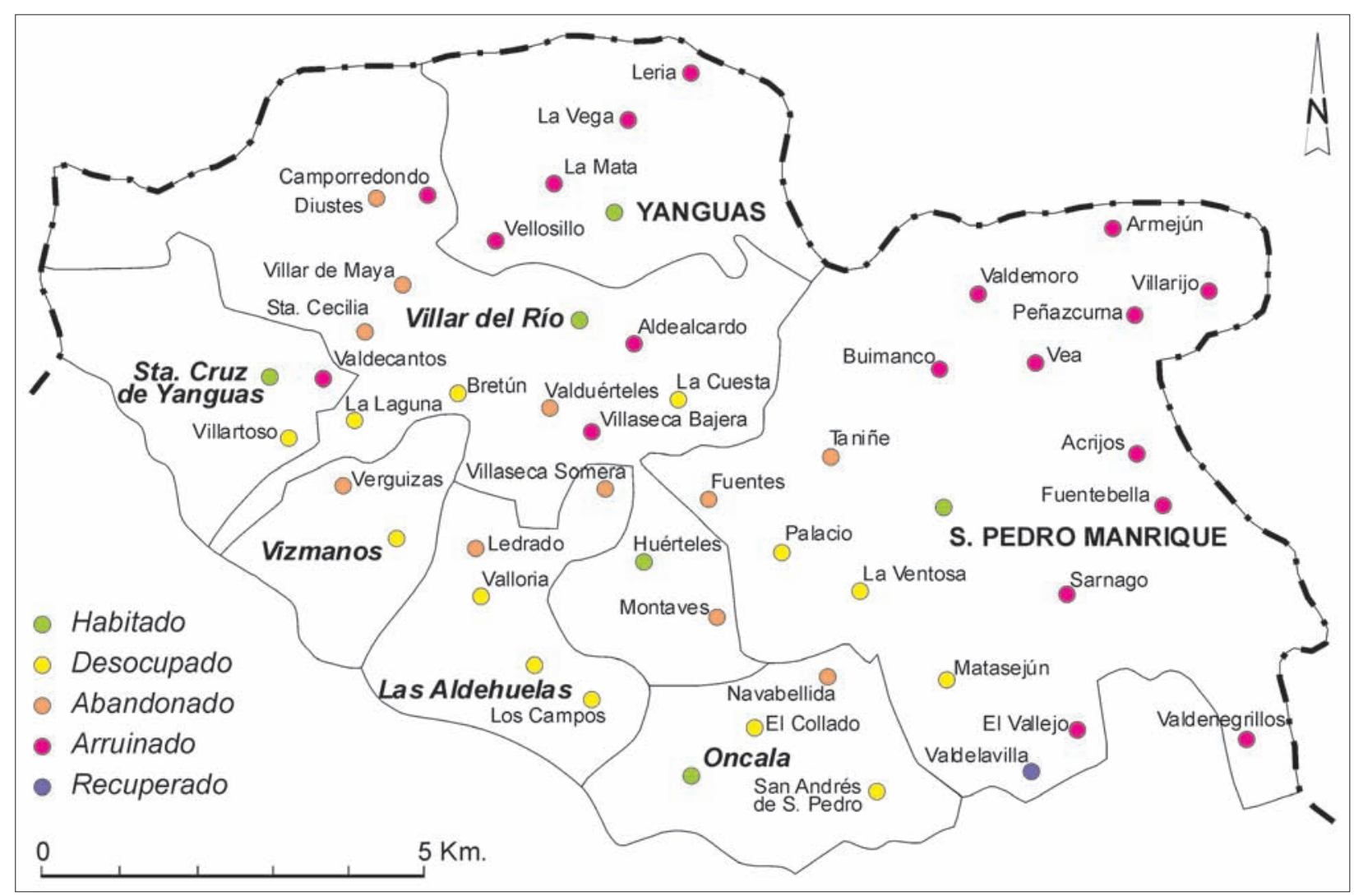

FIg. 8. Pueblos habitados (en verde) y tipos de despoblados en las Tierras Altas de Yanguas y de San Pedro Manrique.

Sin embargo, desde una perspectiva paisajística estas pequeñas agrupaciones de edificios o de ruinas de edificios en las que sólo residen unas cuantas personas o incluso no reside nadie constituyen un componente fundamental que identifica y define visualmente este sector de las Tierras Altas y la comarca en conjunto (Muñoz Jiménez, 2008). Y, aunque se podría pensar que todos presentan el mismo grado de vaciamiento y abandono y que su configuración es muy parecida, estos despoblados presentan en la actualidad una tipología notablemente amplia. Combinando los criterios referentes a la población y al estado del caserío, se diferencian con claridad tres tipos a los que denominamos «pueblos desocupados», «pueblos abandonados» $\mathrm{y}$ «pueblos en ruinas». A ellos hay que añadir un único y peculiar caso de «pueblo recuperado».

\section{LOS PUEBLOS DESOCUPADOS}

Los pueblos desocupados son los núcleos compuestos por entre treinta y ochenta casas que, contando con un bajísimo número de residentes (entre diez y veinticinco en casi todos los casos), presentan unas vías y unas construcciones mayoritariamente en buen estado como consecuencia de un mantenimiento o una restauración suficientes. Ello hace posible que, de forma temporal (en el centro del verano), recuperen de hecho un volumen de población residente (vinculada mayoritariamente a ellos por su origen) próximo al que tenían hace cuarenta años o acojan grupos relacionados con nuevas actividades. A este tipo de despoblados, que también se podrían denominar «pueblos conservados», pertenecen trece núcleos, ocho en la Tierra de Yanguas (Villartoso, Bretún, La Cuesta, La Laguna, Vizmanos, Las Aldehuelas, Los Campos y Valloria) y cinco en la Tierra de San Pedro (El Collado, San Andrés de San Pedro, Matasejún, Palacio de San Pedro y La Ventosa).

Estas entidades suman 213 habitantes (16,4 habitantes por término medio) y en la práctica totalidad de ellas los antiguos vecinos o sus descendientes (que tienen su residencia habitual fuera de la comarca) han mantenido la propiedad de los inmuebles y, en la medida de lo posi- 

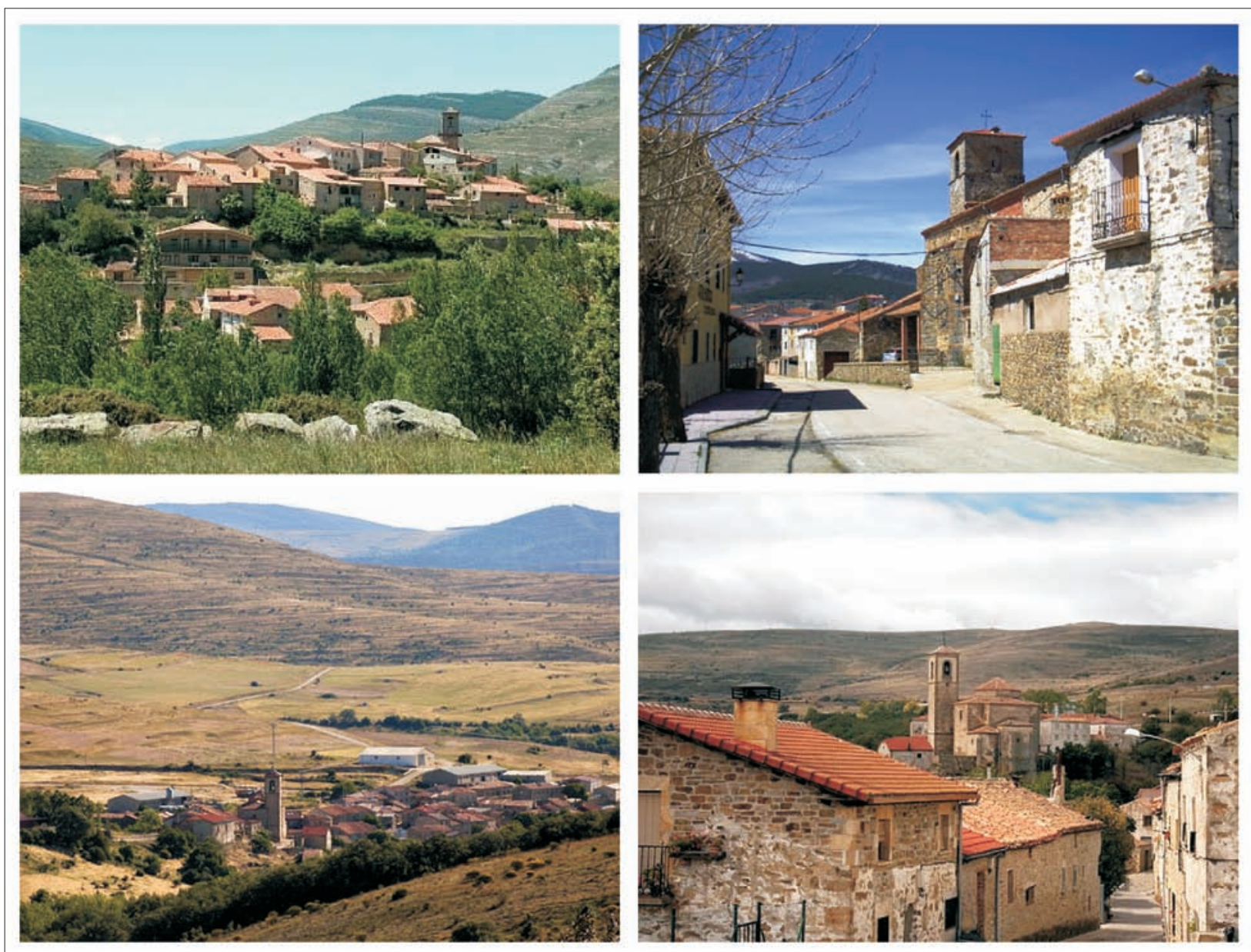

FIG. 9. Dos pueblos habitados: arriba, Santa Cruz de Yanguas (49 habitantes), en la Tierra de Yanguas; abajo, Oncala (51 habitantes), en la Tierra de San Pedro Manrique.

ble, los han conservado en condiciones de habitabilidad o incluso los han reformado y mejorado, al tiempo que la administración provincial los ha asegurado el acceso por carretera y los ayuntamientos a los que pertenecen han dedicado y dedican algunos recursos al cuidado de las calles, al abastecimiento de agua y a otros servicios básicos. Se trata, pues, de entidades despobladas pero no abandonadas, en las que el edificio más importante (la iglesia) permanece casi siempre en pie, conserva su cubierta y su mobiliario y algunos días del año acoge ceremonias religiosas.

Los vecinos que hace cuarenta o cincuenta años residían en estos pueblos actualmente desocupados de las tierras altas de Yanguas y San Pedro no perdieron entonces (por cesión «voluntaria» o expropiación a favor del Patrimonio Forestal del Estado) la propiedad de sus casas y de todas sus tierras, de modo que su emigración fue progresiva sin llegar al abandono y a la desvinculación plena, económica y sentimental, del lugar de origen. La razón principal de ello es que normalmente estos núcleos se localizan en sectores de altitud mediana (entre $1.100 \mathrm{y}$ $1.250 \mathrm{~m}$ ) y pendiente moderada de los valles del Cidacos y el Linares, en los que los que la dinámica erosiva es poco intensa y los suelos presentan un desarrollo y una calidad capaces de sostener una agricultura cerealista suficientemente rentable tras la concentración parcelaria y la correlativa concentración de la explotación. También se sitúan algunos a mayor altura (por encima incluso de los $1.300 \mathrm{~m}$ ), cerca de los puertos y de las áreas de cumbres de topografía alomada donde se conservan los pastizales de calidad aún aprovechables por la ganadería ovina. En todo caso, la repoblación forestal masiva y 

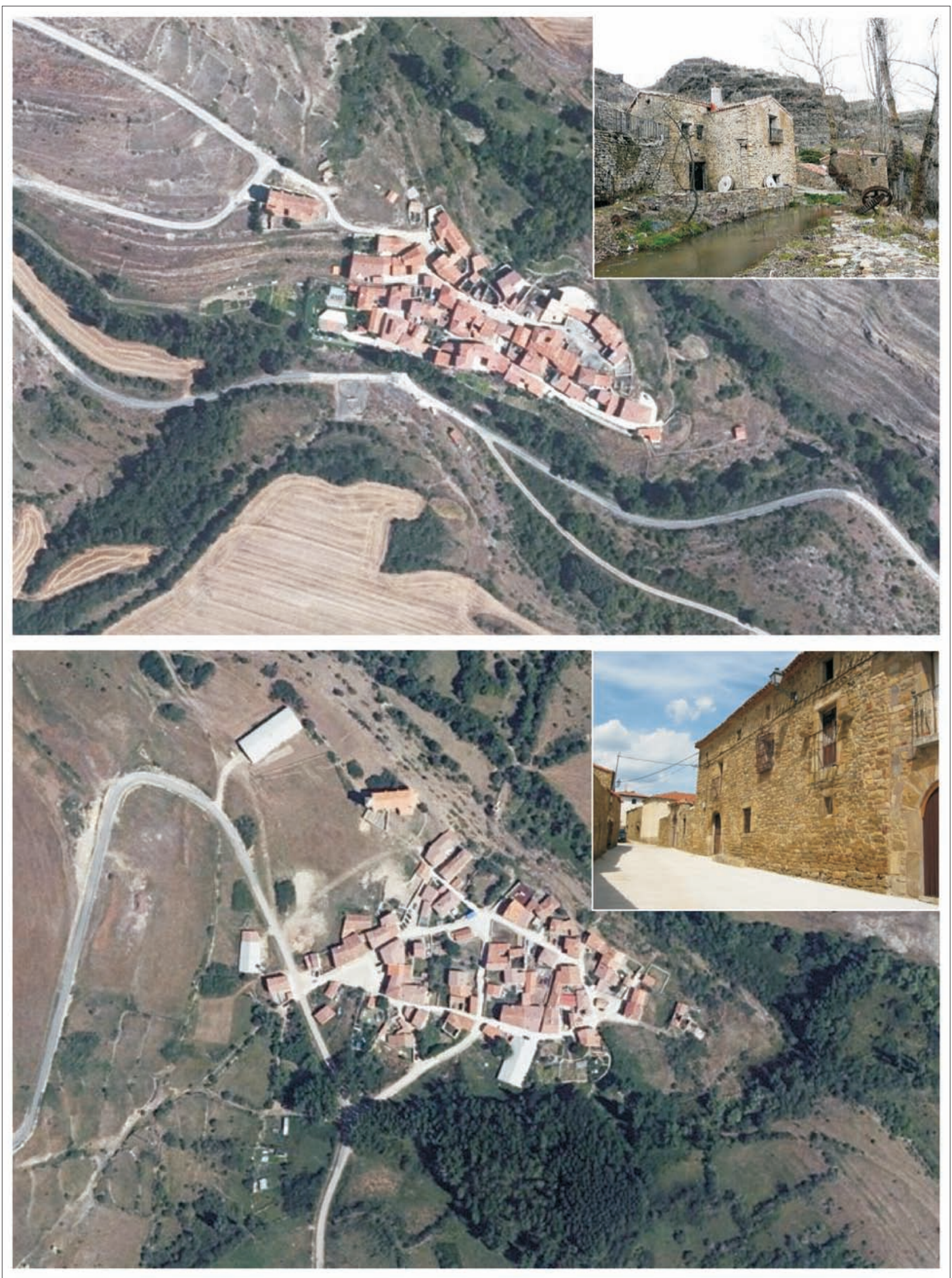

FIg. 10. A la izquierda, imagen aérea (Iberpix 2) y vista interior de dos pueblos desocupados de la Tierra de Yanguas: arriba, Bretún (16 habitantes); abajo, Vizmanos (25 habitantes). A la derecha, imagen aérea (Iberpix 2) y vista interior de dos pueblos desocupados de la Tierra de San Pedro: arriba, Matasejún (14 habitantes); abajo, San Andrés de San Pedro (19 habitantes). 


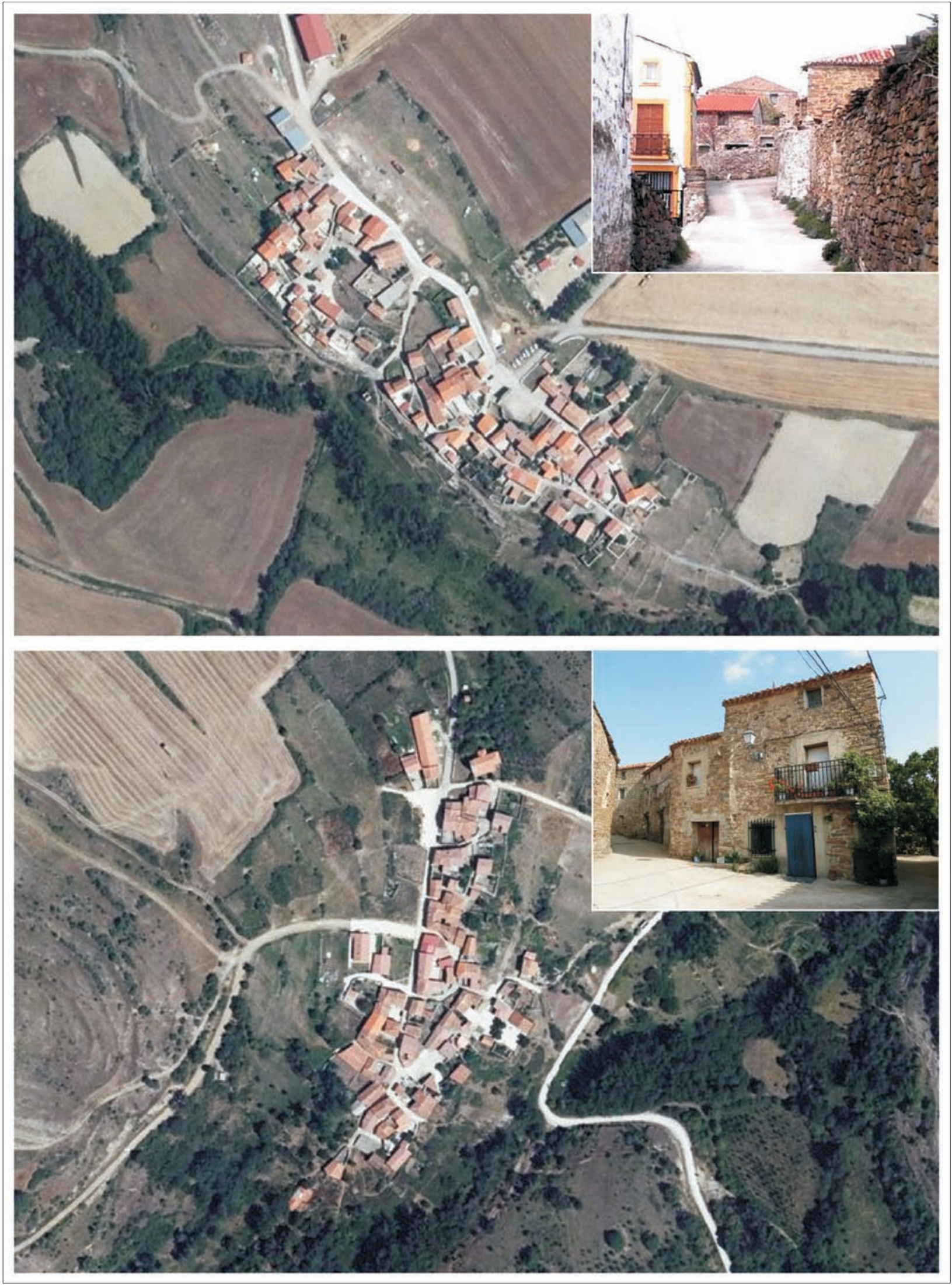



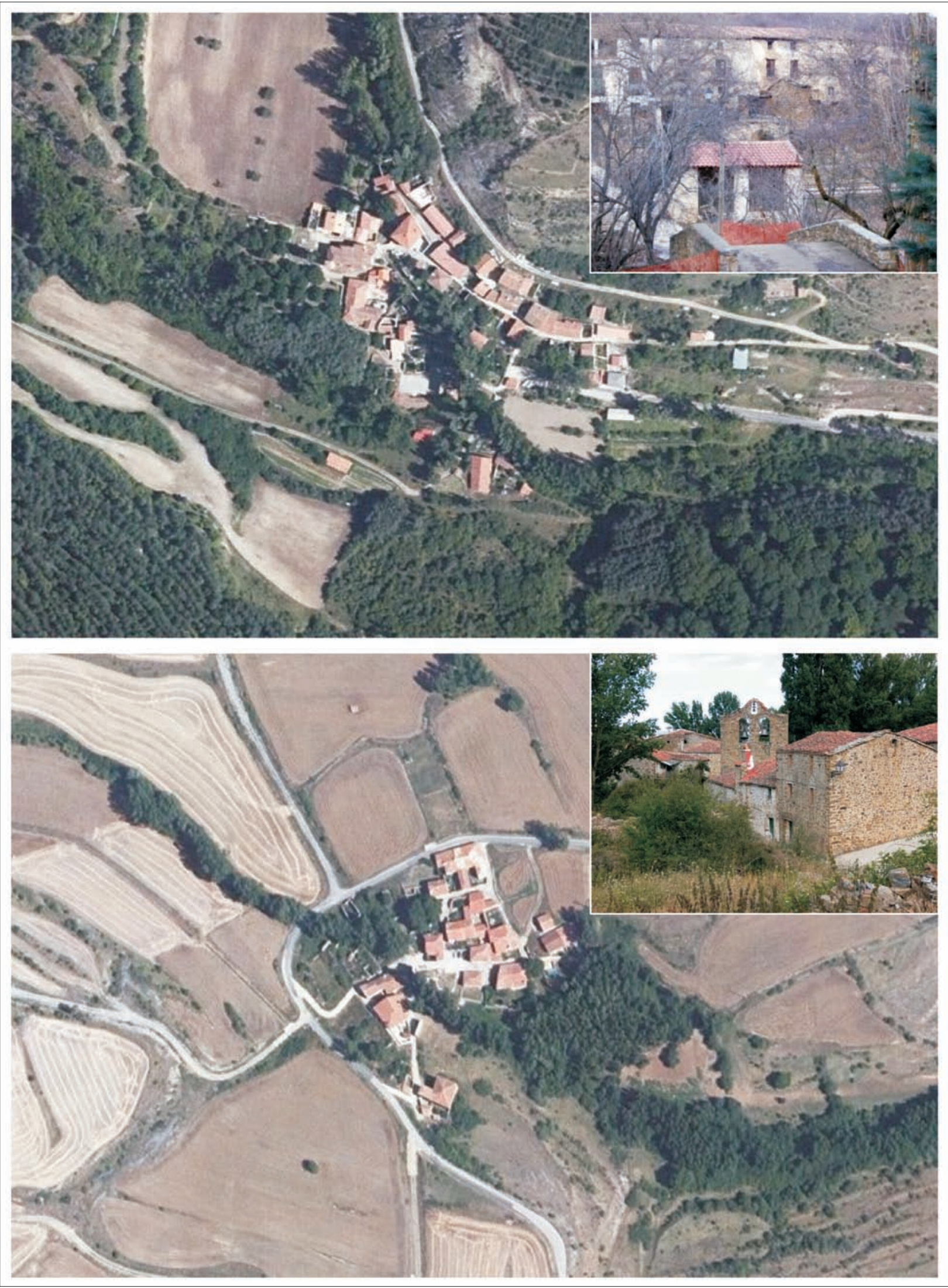

FIG. 11. A la izquierda, imagen aérea (Iberpix 2) y vista interior de dos pueblos abandonados de la Tierra de Yanguas: arriba, Diustes (cinco habitantes); abajo, Santa Cecilia (tres habitantes). A la derecha, imagen aérea (Iberpix 2) y vista interior de dos pueblos abandonados de la Tierra de San Pedro: arriba, Navabellida (cuatro habitantes); abajo, Taniñe (dos habitantes). 


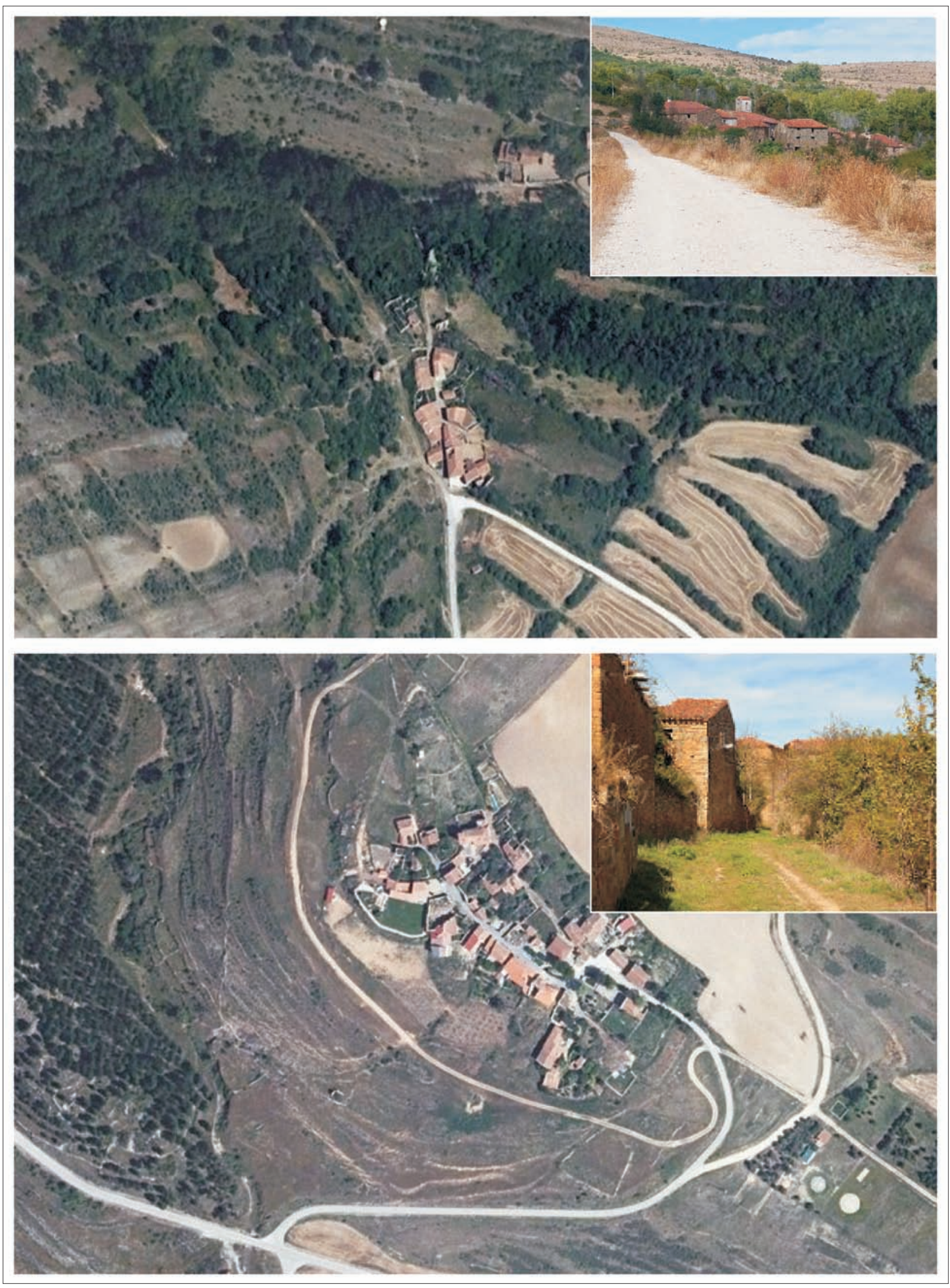




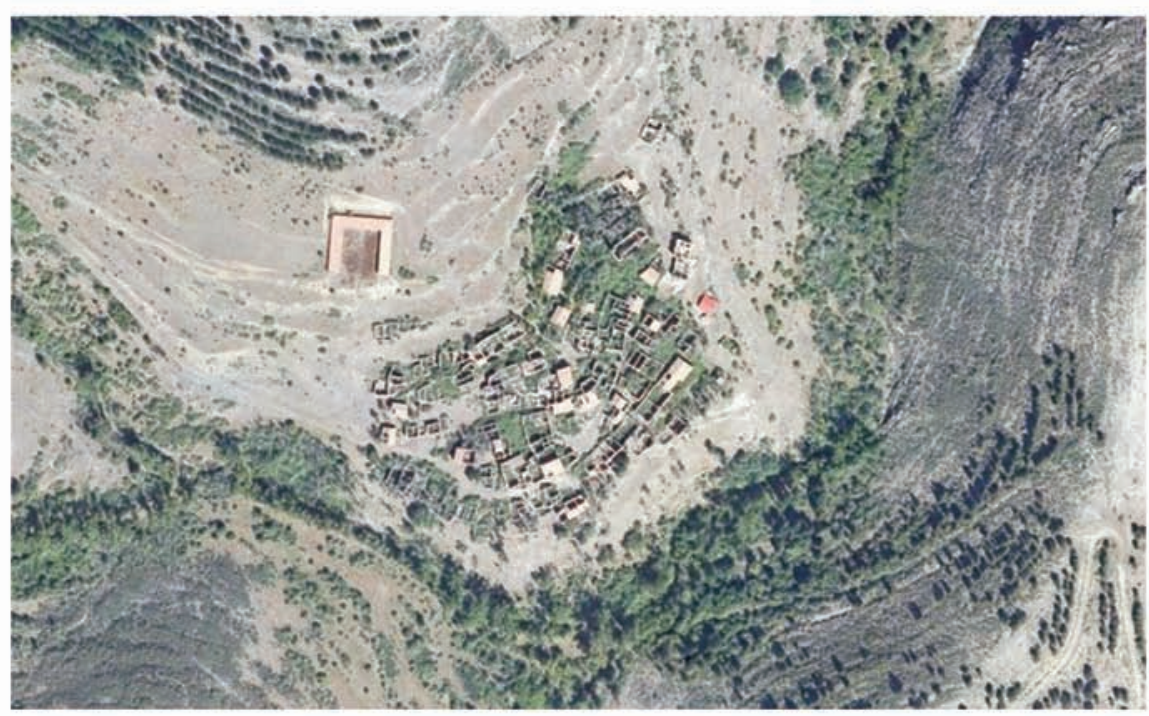

FIG. 12. A la izquierda, imagen aérea (Iberpix 2) de tres pueblos en ruinas de la Tierra de San Pedro: de arriba abajo, Acrijos, Buimanco y Vea (cero habitantes, todos). A la derecha, imagen aérea (Iberpix 2) de tres pueblos en ruinas de la Tierra de Yanguas: de arriba abajo, Aldealcardo, Leria y Vellosillo (cero habitantes, todos).
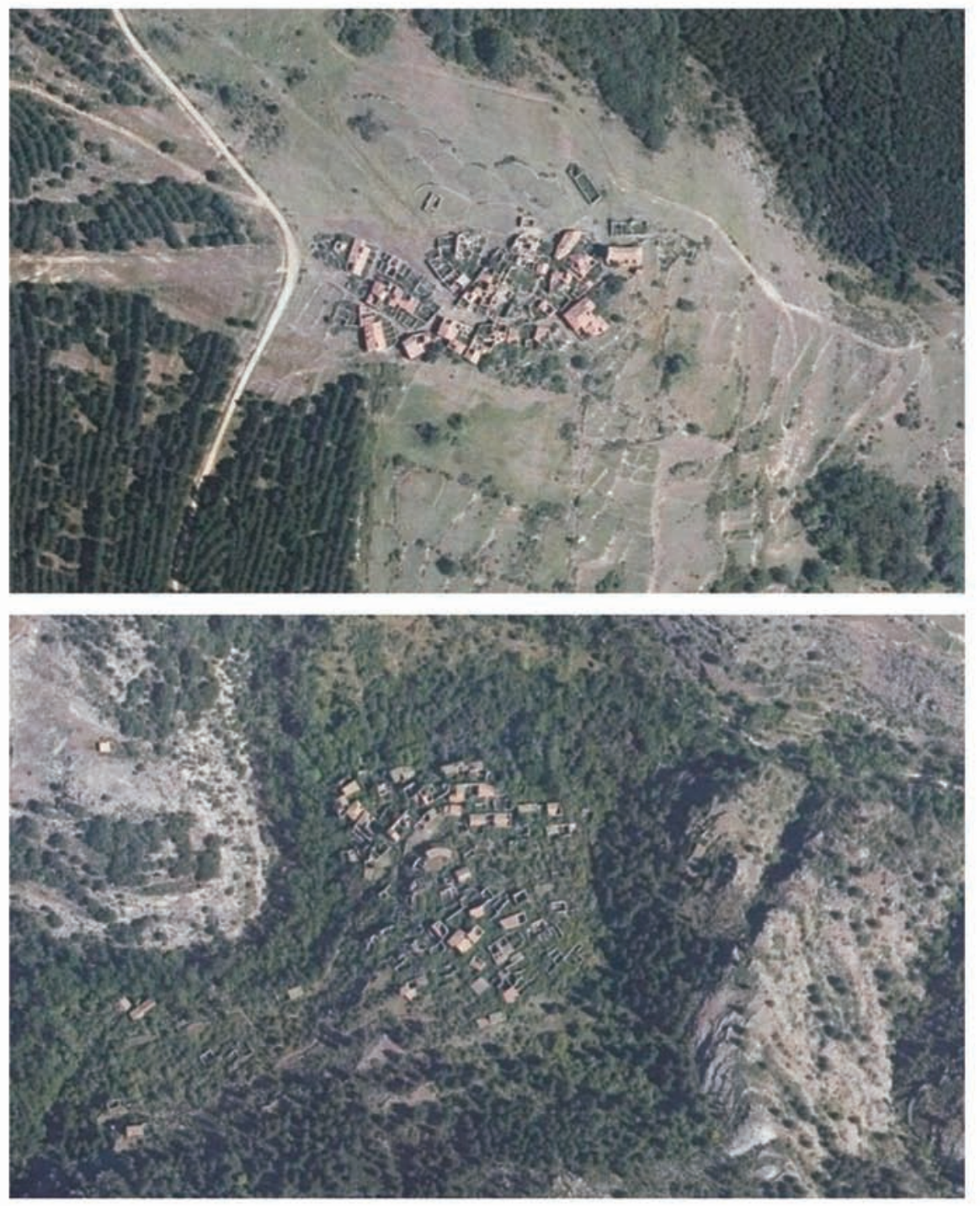

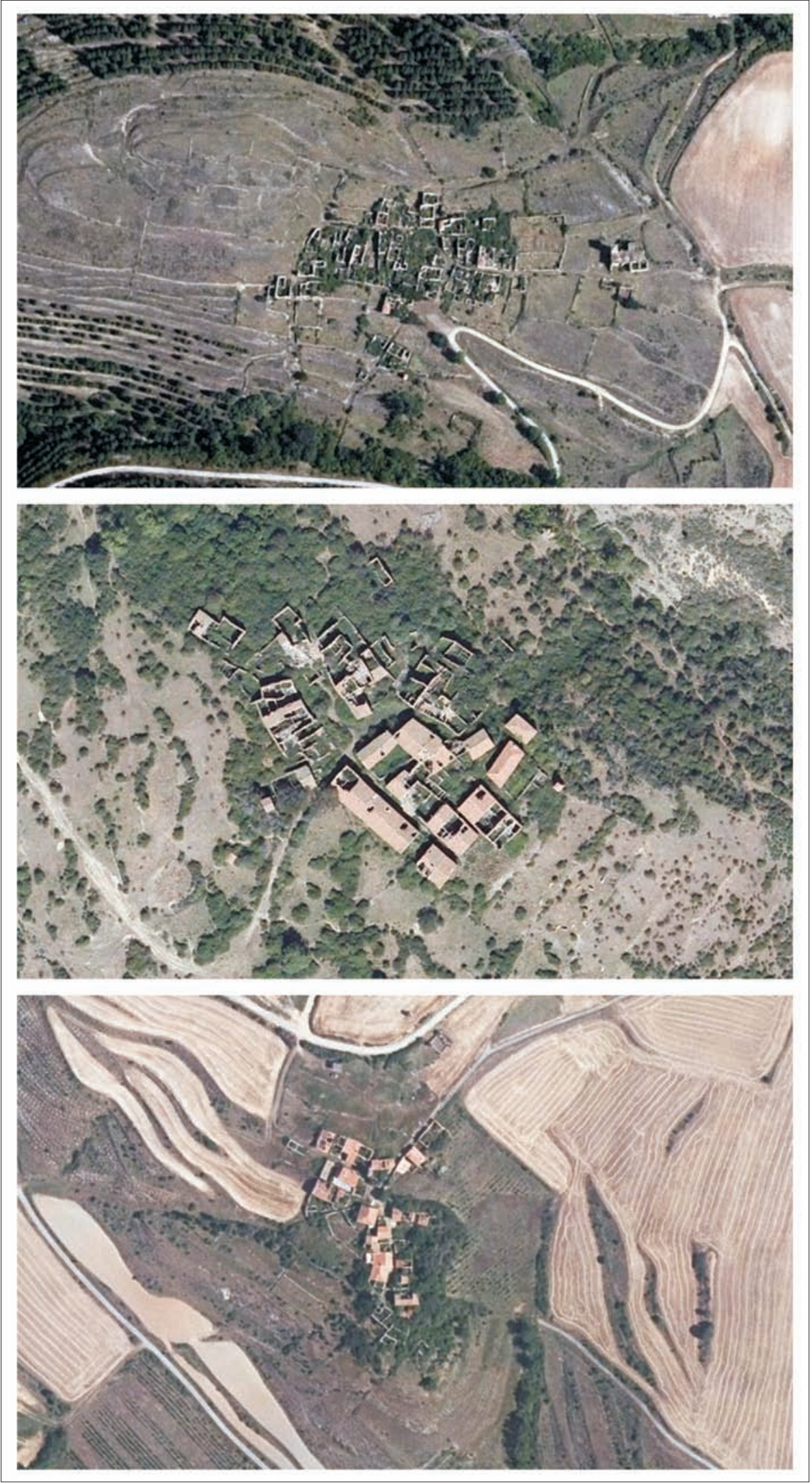
la salida inmediata de los habitantes no se planteó ni se percibió como la única salida social y económicamente viable para el aprovechamiento de sus tierras.

\section{LOS PUEBLOS ABANDONADOS}

Los pueblos abandonados son los núcleos de tamaño similar o ligeramente inferior a los anteriores (entre veinticinco y cincuenta casas) que, contando con algún residente censado (siempre menos de diez y con frecuencia menos de cinco habitantes), muestran un porcentaje muy significativo (entre el $35 \%$ y el $70 \%$ ) de edificaciones deterioradas o con su cubierta hundida y un viario significativamente descuidado, que comienza a ser invadido por la vegetación. Pese al aspecto apreciablemente ruinoso y abandonado del conjunto, en la mayoría de ellos la iglesia se mantiene en pie, aunque no conserva siempre su techumbre y equipamiento interior (altares, asientos, imágenes, etc.), de modo que ya no es apta para el culto.

Se incluyen en este tipo once núcleos, ocho en la Tierra de Yanguas (Diustes, Montaves, Santa Cecilia, Valduérteles, Villar de Maya, Verguizas, Ledrado y Villaseca Somera) y tres en la Tierra de San Pedro (Navabellida, Fuentes de San Pedro y Tañiñe). Este grupo de pueblos suman en la actualidad 42 habitantes (3,8 habitantes por término medio) y, pese al vacío demográfico prácticamente total que registran, en ellos se mantienen aún algunos inmuebles en condiciones habitables (que son ocupados algunas semanas de verano) o susceptibles de recuperación.

Entre ellos hay pueblos cuyos términos se cedieron en los años sesenta para su repoblación forestal, pero que, al contar entonces con unos efectivos demográficos importantes para la zona (superiores incluso a los 150 habitantes), han ido dilatando su vaciamiento. También los hay que no se vieron afectados por la plantación de coníferas o lo hicieron de forma parcial pero que, al tener entonces una población muy baja y un terrazgo pequeño, han registrado un abandono que, aun siendo lento y progresivo, los ha llevado a alcanzar a finales del siglo xx el estado de vaciamiento que los caracteriza. En el primero de los casos se trata de cabeceras de antiguos municipios relativamente extensos y de situación marginal que incluían sectores montañosos importantes, elevados y particularmente accidentados. En el segundo, se trata de cabeceras de antiguos municipios de pequeña extensión y de altitud y pendiente medias o moderadamente altas en los que la explotación agrícola presentaba dificultades e incluso no resultaba viable la concentración parcelaria. Todos sin excepción tienen acceso por carretera y son ob- jeto de una mínima atención por parte de la administración local y provincial.

\section{LOS PUEBLOS EN RUINAS}

Los pueblos en ruinas, finalmente, son los núcleos totalmente vacíos de población (sólo uno de ellos tiene una persona empadronada), cuyo viario se encuentra en total abandono y la práctica totalidad de cuyos edificios (incluida la iglesia) se han venido abajo, no tienen cubierta y están invadidos (lo mismo que lo que fueron calles) por la vegetación (zarzas, durillos, rosales silvestres, helechos, e incluso árboles). Además, casi todos estos conjuntos ruinosos e inhabitables compuestos por los restos de varias decenas de casas (alrededor de un centenar en algún caso) son también inaccesibles, ya que sólo se puede llegar a la práctica totalidad de ellos por pista o incluso por senda. A este tipo pertenecen la mayor parte y los más característicos de los despoblados del área estudiada: suman diecinueve, de los cuales ocho se encuentran en la antigua Tierra de Yanguas, vertiente al río Cidacos (Leria, La Mata, La Vega, Vellosillo, Aldealcardo, Camporredondo, Valdecantos y Villaseca Bajera) y once se localizan en la antigua Tierra de San Pedro, vertiente al río Linares (Acrijos, Armejún, Buimanco, Fuentebella, Peñazcurna, Sarnago, Valdemoro, Valdenegrillos, El Vallejo, Vea y Villarijo).

Estos despoblados ruinosos se localizan sobre todo en los sectores más accidentados y marginales del área (especialmente en el borde septentrional), donde el cultivo resulta particularmente difícil y poco productivo, y corresponden en casi todos los casos a pueblos cuyos habitantes optaron por responder positivamente a la oferta de la Operación San Pedro Manrique y vendieron al Estado a finales de los años sesenta del siglo pasado las tierras de sus término para su reforestación y renunciaron colectivamente a la propiedad de sus casas. En ellos la emigración fue muy rápida y masiva: entre 1960 y 1970 perdieron el $87 \%$ de su población (pasaron en conjunto de 1.330 a 174 habitantes), la mitad de ellos ya estaban vacíos en este último año y hubo núcleos que comenzaron la década con más de un centenar (o incluso varios centenares) de habitantes (como Sarnago, Villarijo, Vea, Fuentebella y La Vega) y la terminaron con sólo una o unas pocas decenas de residentes o incluso totalmente despoblados. Este drástico abandono, junto con el nulo interés de Patrimonio Forestal del Estado por conservar el caserío y el viario de los pueblos que había adquirido, llevó a un deterioro acelerado de los edificios (hasta el 


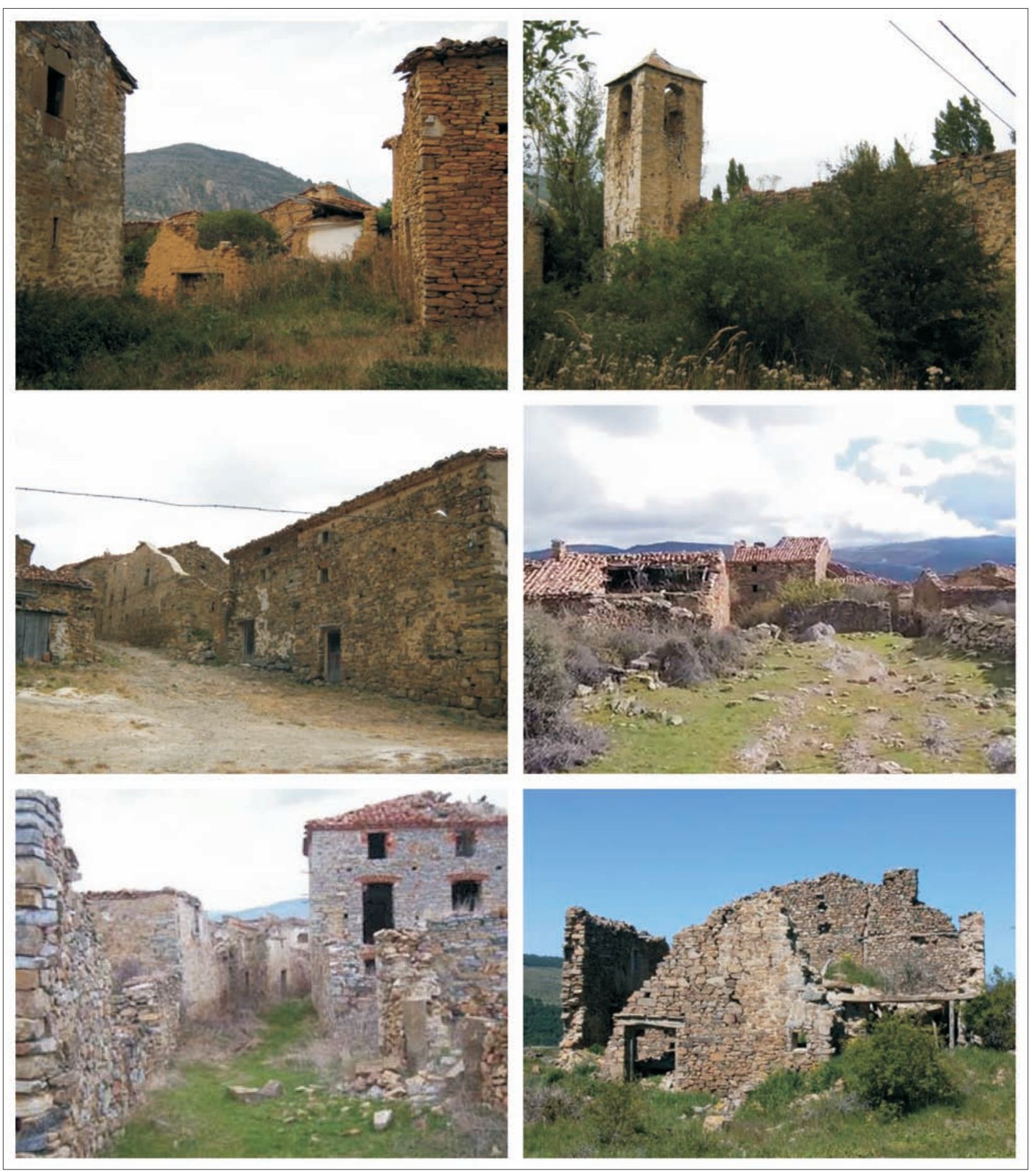

Fig. 13. De izquierda a derecha, y de arriba abajo, vista interior de seis pueblos en ruinas vacíos de las Tierras Altas de Yanguas y de San Pedro Manrique: Vellosillo, Camporredondo, Sarnago, Buimanco, Aldealcardo y Villaseca Bajera. 


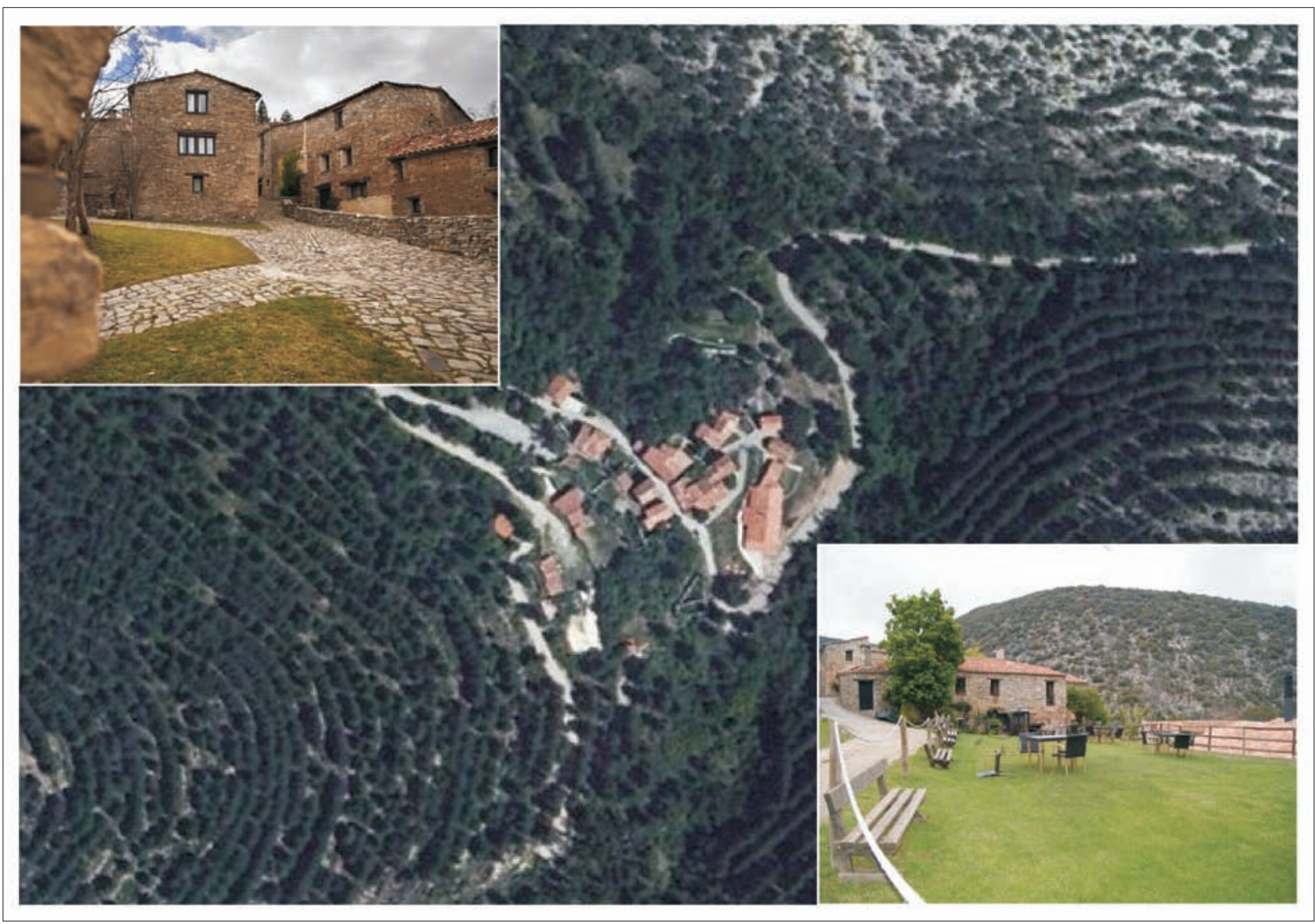

Fig. 14. Imagen aérea (Iberpix 2) y vistas interiores del único pueblo recuperado de las Tierras Altas de Yanguas y de San Pedro Manrique: Valdelavilla (cero habitantes empadronados).

hundimiento de la práctica totalidad de ellos, incluida la iglesia) y permitió que la vegetación invadiese (hasta cegarlas en muchos casos) las antiguas calles y sendas.

\section{El ÚNICO CASO DE PUEBLO RECUPERADO}

Al tipo que se acaba de describir perteneció también hasta los últimos años del siglo xx el único y muy interesante caso de pueblo recuperado o restaurado que se encuentra en el área: Valdelavilla, perteneciente al municipio de San Pedro Manrique. Este pequeño núcleo de población compuesto por una quincena de casas y habitado hasta 1950 por algo menos de medio centenar de personas, que quedó totalmente vacío en 1968, fue adquirido en 1996 (cuando se encontraba ya en total ruina) por una empresa con el objetivo de transformarlo en «complejo turístico rural». Esta empresa, denominada Sociedad Tierras Altas, S. A., financiada por las cajas de aho- rros con mayor implantación provincial y participada por la administración municipal de la comarca, llevó a cabo la reconstrucción o restauración de todos sus edificios (salvo la iglesia) y los ha dedicado o los ha cedido para diversos usos: hostelero, turístico o incluso docente (enseñanza intensiva de la lengua inglesa). Es éste el único caso en que un núcleo de población del área, después de que sus vecinos lo abandonaran y entregaran su término a Patrimonio Forestal del Estado, ha sido recuperado y reactivado (con mayor o menor fortuna) pero sin que ello haya significado su repoblación, ya que no ha vuelto a tener ningún habitante censado.

\section{CONCLUSIONES: DESPOBLACIÓN Y DESPOBLADOS EN LAS TIERRAS ALTAS}

Las Tierras Altas de Yanguas y de San Pedro Manrique constituyen un territorio en el que la crisis de la 
economía agropecuaria tradicional, la emigración masiva y la reforestación indiscriminada han tenido como consecuencia, no sólo alteraciones sustanciales en la composición y la estructura de la población, sino cambios drásticos en el poblamiento, que en la actualidad está constituido muy mayoritariamente (en un $88 \%$ ) por pueblos que no tienen habitantes o sólo cuentan con ínfimo número de ellos.

La red de entidades despobladas que ahora se observa coincide con la red de núcleos de población de pequeño tamaño que ya existía a finales de la Edad Media y funcionó con mucha eficacia hasta comienzos del XIX controlando el aprovechamiento de los pastos de verano por los rebaños de la Mesta. Estos pueblos estuvieron habitados y regularmente mantenidos hasta mediados del pasado siglo y, a partir de 1960-1970, se vieron afectados por un proceso emigratorio que en pocas décadas (o, con frecuencia, en pocos años) los dejó práctica o totalmente vacíos. Las causas o principales de este hundimiento demográfico (además de las que con carácter general afectaron a toda España) fueron la consumación de la crisis de la ganadería lanar trashumante (que durante siglos había sido el fundamento económico de la zona), la sobrepoblación derivada de los escasos rendimientos del sistema de cultivo y aprovechamiento vigente (que había intentado compensarla o reemplazarla) y la aplicación de una política tendente a la concentración de la población en un corto número de núcleos viables, a la agrupación de los municipios, a la concentración parcelaria y, en especial, a la reforestación con coníferas (cuyos resultados no han estado a la altura de lo que se pretendía).

El tiempo y el modo en que se produjo la salida de los habitantes y el abandono de las casas en cada uno de los 44 despoblados de las Tierras Altas de Yanguas y de San Pedro Manrique ha hecho que el estado que hoy presentan y el aspecto que muestran no sea siempre el mismo: dieciocho de ellos están vacíos y en ruinas y ya no son recuperables salvo tras una costosa recuperación y restauración (que sólo en un caso se ha intentado), once mantienen una ínfima población y se encuentran descuidados y parcialmente arruinados, siendo posible aún recuperar en algunas construcciones un mínimo de condiciones de habitabilidad, y, finalmente, trece pueblos cuentan con una o dos decenas de residentes y conservan la mayor parte de su caserío en condiciones aceptables de uso, pudiendo acoger (llegado el caso) un número de residentes próximo al que llegaron a tener cuando estaban ocupados.

Dado su alto número, su notable densidad y su reparto por toda el área (con excepción de los sectores, poco extensos, situados por encima de los $1.400 \mathrm{~m}$ de altitud), este variado conjunto de despoblados es un elemento básico del paisaje y está dotado de un alto significado geográfico: las Tierras Altas sorianas (y en concreto las ubicadas en los altos valles del Cidacos y el Linares) son percibidas como un ámbito marcado por el abandono y la ruina de los pueblos, donde las negativas consecuencias de la emigración y la crisis demográfica de la segunda mitad del siglo xx saltan a la vista con especial claridad.

\section{BIBLIOGRAFÍA}

AlCAide Jiménez, J. M. (2000): «Señorío, trashumancia y conflictividad social en la sierra de Yanguas (siglos XVIII-XIX)». Historia Social, núm. 38, pp. 73-94.

Anes, G., y Á. GArcía SÁINZ (coord.) (1994): Mesta, trashumancia y vida pastoril. Fundación Duques de Soria, Soria.

ArChILla, R. (1987): Características climáticas y agrícolas de la provincia de Soria. Diputación Provincial de Soria, Soria.

Asenjo GonzÁlez, M. (1999): Espacio y sociedad en la Soria medieval (siglos XIII-XV). Diputación Provincial de Soria, Soria.

Bachiller Martínez, J. (2008): «Crisis y cambio en la montaña ibérica castellana. Estudio de dos comarcas con marcados contrastes geográficos: Pinares y Tierras Altas». Polígonos. Revista de Geografía, núm. 18, pp. 225-250.

- y M. ${ }^{\text {a }}$ C. SANCHO DE FRANCISCO (1990): Introducción al estudio del espacio geográfico soriano. Asociación de Amigos del Museo Numantino, Soria.

Córdoba Largo, A. (1983): La despoblación en Soria: sus causas y efectos. Ingrabel, Almazán.

Diago Hernando, M. (2002): Mesta y trashumancia en Castilla (siglos XIII a XIX). Arco/Libros, Madrid.

García Fernández, J. (1986): El clima en Castilla y León. Ámbito, Valladolid.

Goig Soler, I. (2002): El lado humano de la despoblación. Centro Soriano de Estudios Tradicionales, Soria.

- y L. Goig Soler (1996): Soria pueblo a pueblo. Gráficas Signo, Soria.

HernándeZ, Abel (2008): Historias de la Alcarama. Gadir, Madrid.

- (2009): El caballo de cartón. Gadir, Madrid.

- (2011a): Leyendas de la Alcarama. Gadir, Madrid.

- (2011b): El canto del cuco. Llanto por un pueblo. Gadir, Madrid.

Hernández, Avelino (1982): Soria, donde la vieja Castilla se acaba. Ediciones de la Torre, Barcelona. 
- (2010): La sierra del Alba. Asociación de Amigos de Avelino Hernández, Soria.

KleIN, J. (1994): La Mesta: estudio de la historia económica española, 1273-1836. Alianza, Madrid.

MAnRIQUe de LARA, G. (1970): «Datos para la historia de la villa de San Pedro Manrique». Celtiberia, núm. 39, pp. 31-66.

MARTín JimÉNEZ, M. I. (2004): «La política territorial y las áreas de montaña. El ejemplo de las áreas de montaña de Castilla y León». Revista de Economía y Finanzas de Castilla y León, vol. 9, pp. 99-122.

- (2008): «Pueblos vacíos, atonía y envejecimiento en la comarca soriana de Tierras Altas y valle de Tera». Ería. Revista Cuatrimestral de Geografía, núm. 75, pp. 113-128.

Monge, C. (1964): «Veintiocho pueblos de la provincia, en transformación». $A b c$ (Madrid), 30 de abril de 1964, p. 74.

- (1965): «Nueva ordenación agraria en las comarcas sorianas de Yanguas y San Pedro Manrique». Abc (Madrid), 11 de diciembre de 1965, p. 87.

MuÑoz Jiménez, J. (2008): Catálogo de los paisajes de la provincia de Soria. Tierras Altas. Fundación Duques de Soria, Soria (inédito).
ORTEGA VILlazÁN, M. T. (1992): El clima del sector norte de la cordillera ibérica. Universidad de Valladolid, Valladolid.

Pérez GuineA, M. C. (1982): Estudio sobre la sociedad soriana en el siglo XVIII. Consejo General de Castilla y León, Valladolid.

Pérez Romero, E. (1995): Patrimonios comunales, ganadería trashumante y sociedad en la Tierra de Soria: siglos XVIII-XIX. Consejería de Educación y Cultura, Valladolid.

Río, M. del (1828): Vida pastoril. Imprenta de Repullés, Madrid.

Ruiz, E. (2001): Historia económica de Soria. Centro de Estudios Sorianos (CSIC), Soria.

Ruiz Martín, F., y Á. García Sáinz (eds.) (1998): Mesta, trashumancia y lana en la España moderna. Crítica/ Fundación Duques de Soria, Barcelona.

Sanz Pérez, E., y C. Pascual Arribas (2001): «Paisaje geológico de la provincia de Soria», en R. Nuche del Rivero (ed.): Patrimonio geológico de Castilla y León. Enresa, Madrid, pp. 278-303.

SAnZ SÁnchez, A. (2001): «Demografía de la Soria rural durante el siglo xx». Celtiberia, núm. 94, pp. 101131. 